\title{
Cue Interactions in Flavor Preference Learning: A Configural Analysis
}

\author{
Dominic M. Dwyer \\ Cardiff University
}

\author{
Mark Haselgrove and Peter M. Jones \\ University of Nottingham
}

\begin{abstract}
Four experiments showed that the preference normally established to a neutral flavor cue that was paired with maltodextrin was attenuated when that cue was conditioned in compound with another flavorovershadowing. Furthermore, two experiments showed that the preference for a neutral flavor conditioned as part of a compound was further attenuated if the other element in that compound was separately paired with the reinforcer-blocking. These results stand in contrast to a number of previous compound flavor preference conditioning experiments, which have not revealed reliable cue competition effects. These discrepant findings are discussed in terms of the effects of within-compound associations and a configural perspective on potentiation. Modeling of this configural perspective predicts that a compound of two separately trained cues will elicit a similar response to the individual cues themselves-absence of summation. Two experiments confirmed this prediction.
\end{abstract}

Keywords: overshadowing, blocking, summation, potentiation, flavor preference learning, configural learning, within-compound association

Animals can acquire a preference for a neutral flavor if it is paired with a substance that evokes an unconditioned appetitive response. For example, Holman (1975) showed that rats acquired a preference for drinking a flavor that had been paired with a concentrated solution of saccharin over another flavor paired with a weaker solution of saccharin. Similarly, Sclafani and Ackroff (1994) have shown that rats will learn a preference for a flavor that is paired with glucose or fructose, and Elizalde and Sclafani $(1988,1990)$ have shown a similar preference for flavors that have been paired with the hydrolyzed starch, polycose. Although such basic conditioning effects are reliable, the functional properties of flavour preference conditioning have been the subject of considerable debate. For example, although flavor preference learning has often been found to be particularly resistant to extinction (e.g., Capaldi, Myers, Campbell, \& Sheffer, 1983; Drucker, Ackroff, \& Sclafani, 1994; Elizalde \& Sclafani, 1990; Harris, Shand, Carroll, \& Westbrook, 2004), with more powerful designs it is possible to observe effects of conditioned stimulus (CS) alone presentations following flavour preference conditioning (e.g., Delamater, 2007). Similarly, although Campbell, Capaldi, Sheffer, and Bradford (1988) could find no evidence for contextual specificity of flavor preference learning, Dwyer and Quirk (2008) demonstrated that with more sensitive procedures rats could indeed learn preferences that were conditional upon the training context.

Dominic M. Dwyer, School of Psychology, Cardiff University; and Mark Haselgrove and Peter M. Jones, School of Psychology, University of Nottingham.

Experiments 1A \& 1B were funded by a Royal Society Research Grant to Dominic M. Dwyer and were performed when Dominic M. Dwyer was a research fellow at Churchill College, Cambridge. Experiments 1C, 2A, $3 \mathrm{~A}, \& 3 \mathrm{~B}$ were funded by a BBSRC new investigator grant to Dominic $\mathrm{M}$. Dwyer. Experiments $2 \mathrm{~B}$ and $2 \mathrm{C}$ were funded by a BBSRC new investigator grant to Mark Haselgrove.

Correspondence concerning this article should be addressed to Dominic M. Dwyer, School of Psychology, Cardiff University, Cardiff CF10 3AT, United Kingdom. E-mail: dwyerdm@cardiff.ac.uk
The initial goal of the current experiments was to examine a further source of ambiguity in the literature on flavor preference learning - cue-competition. Pavlov (1927) was the first to report cue competition with his description of overshadowing in dogs. In this experiment a compound of a thermal stimulus of $0{ }^{\circ} \mathrm{C}$ and tactile stimulation of the skin was paired with the consumption of a dilute acid. The conditioned response of salivation was substantial during the presentation of the compound, yet when the thermal stimulus was presented alone, no salivation was detectedlearning about the thermal stimulus was said to have been overshadowed by the tactile stimulus. Overshadowing is a robust property of Pavlovian conditioning, having been demonstrated in rats in studies of conditioned suppression (Kamin, 1969; Mackintosh, 1971), flavor aversion learning (Revusky, 1971), appetitive conditioning (Holland, 1999), and spatial learning (Pearce, Graham, Good, Jones, \& McGregor, 2006). It has also been demonstrated in species as diverse as goldfish (Tennant \& Bitterman, 1975) and humans (Chamizo, Aznar-Casanova, \& Artigas, 2003). Whether overshadowing is a reliable phenomenon in flavor preference learning is, however, less clear. Holder (1991) reported an experiment in which rats in an odor/taste group received paired presentations of a compound of an odor and a taste stimulus with a sucrose Unconditioned Stimulus (US). Rats in an odor group and a taste group received paired presentations of either just an odor with the US, or just the taste with the US. In two-bottle preference tests in which the odor, or the taste, was presented alongside another odor or taste that had not been paired with sucrose, animals in the odor/taste group demonstrated equivalent preferences for the taste and odor that had been paired with sucrose as the animals in the odor group and the taste group. In their Experiment 1, Capaldi and Privitera (2008) gave rats in an odor/taste group pairings of one odor/taste compound with a $20 \%$ polycose solution and pairings of another odor/taste compound with a $2 \%$ polycose solution. Other animals received pairings of one taste with $20 \%$ polycose, and another taste with $2 \%$ polycose (taste group), or pairing of one odor with $20 \%$ polycose and another odor with $2 \%$ polycose (odor 
group). In two-bottle tests the odors or tastes paired with the $20 \%$ and $2 \%$ polycose solutions were presented. The results indicated that rather than overshadowing, the taste in fact potentiated learning about the odor in the odor/taste group, relative to the odor group. Consistent with the results of Holder this experiment also showed that there was no difference in the preference for the taste between the odor/taste group and the taste group ${ }^{1}$. The results of Holder (1991) and of Capaldi and Privitera (2008) therefore suggest that flavor preference learning is not susceptible to overshadowing, and under some circumstances can generate the exact opposite result.

To the best of our knowledge, there exists only one experiment that is consistent with the idea that flavor preference learning is susceptible to overshadowing. Capaldi and Hunter (1994) gave rats in a taste group paired presentations of one taste with sucrose and another taste with saccharin. Rats in an odor/taste group received pairings of one odor/taste compound with sucrose and pairings of another odor/taste compound with saccharin. All animals were then given two-bottle preference tests between the substances paired with sucrose and saccharin. Animals in the taste group showed a significant preference for the taste paired with sucrose over the taste paired with saccharin. This effect was not present in animals in the odor/taste group: for these animals the two tastes were consumed at equivalent levels. Although it is tempting to conclude that these results are evidence for overshadowing of flavor preference learning, it should be noted that during training animals in the taste group drank significantly more than animals in the odor/taste group - an effect that seemed largely due to the taste group consuming more of the taste paired with sucrose than did the odor/taste group. If the difference that was evident during training persisted during testing, then it may have generated an effect that resembled, but which was not, overshadowing. Moreover, when the odor/taste group were tested with the odors their preferences were as large as those in animals trained with the odors alone. Taken together, these results suggest that the odor/taste compound generalized perfectly to the odor but not at all to the taste.

The second form of cue-competition we examine here is blocking. The seminal demonstration of blocking was reported by Kamin (1969) in a two-stage procedure where one group of animals received parings of a noise and electric shock while a second group did not; both sets of animals then received pairings of a light/noise compound with electric shock before being tested with the light alone-suppression of ongoing responding by the light was negligible when the noise alone had been paired with shock prior to the compound training phase but was substantial when the noise had not been trained in this fashion. That is, prior training with one element of a compound is said to have blocked learning about the other. As with overshadowing, blocking has been observed in a large variety of species and preparations. For example, blocking has been reported in rats using appetitive Pavlovian conditioning (e.g., Dopson, Pearce, \& Haselgrove, 2009), tasteaversion conditioning (Willner, 1978) and spatial learning (Pearce et al., 2006; Rodrigo, Chamizo, McLaren, \& Mackintosh, 1997). Furthermore, there is evidence of blocking in species as diverse as honeybees (Blaser, Couvillon, \& Bitterman, 2008), goldfish (Tennant \& Bitterman, 1975), and humans (Dickinson, Shanks, \& Evenden, 1984; Le Pelley, Oakeshott, \& McLaren, 2005). Consistent with the widespread reports of blocking across many conditioning procedures, both Holder (1991) and Balleine, Espinet, and
Gonzalez (2005) report results consistent with blocking in flavor preference learning. However, there is also a report of a failure to observe blocking by Capaldi and Hunter (1994): in the paper already considered above they reported that prior training with tastes had no effect on responding to odors that were subsequently trained as part of an odor/taste compound-that is, no blocking was observed.

Given the inconsistencies in prior studies of cue-competition in flavor preference learning, the initial purpose of the first six experiments reported here was to determine whether flavor preference learning is subject to overshadowing and blocking. In Experiments $1 \mathrm{~A}$ and $1 \mathrm{~B}$ we used a between-subjects methodology to investigate whether overshadowing can be seen between aqueous odors (Experiment 1A) or tastes (Experiment 1B). Experiment $1 \mathrm{C}$ used similar stimuli and methods to Experiment $1 \mathrm{~A}$ to assess blocking. Experiments $2 \mathrm{~A}$ and $2 \mathrm{~B}$ used a within-subjects methodology to investigate whether Kool-Aid flavors (which comprise both taste and odor) will overshadow one another. Experiment $2 \mathrm{C}$ examined blocking of flavor preference in a within-subjects design using Kool-Aid flavors. On the basis of the experiments reported by Holder (1991) and by Capaldi and Privitera (2008) it might reasonably be expected that these experiments will either fail to reveal overshadowing, or potentially, reveal the opposite result. But to foreshadow the results described below, overshadowing was observed in all of our experiments. Similarly, despite the contrasting expectations suggested by previous investigations of blocking in flavor preference learning (Balleine et al., 2005; Capaldi \& Hunter, 1994; Holder, 1991), blocking was also observed in each experiment. We then outline a configural model that can account for the discrepancies among studies of cue-competition in flavor preference learning. Finally, we test a prediction derived from this model with two summation experiments.

\section{Experiments 1A, 1B, \& 1C}

Experiments $1 \mathrm{~A}$ and $1 \mathrm{~B}$ both employed the same betweensubjects overshadowing design while Experiment $1 \mathrm{C}$ employed a between-subjects blocking design (see Table 1). In Experiments 1A and 1B Group Overshadow received cue solutions A and B in simultaneous compound with maltodextrin, a hydrolyzed starch product similar to the polycose used by others (e.g., Elizalde \& Sclafani, 1990; Capaldi \& Privitera, 2008). Group Paired-Control received cue solution A with maltodextrin, and Group UnpairedControl received cue solution A and maltodextrin separately. In Experiment 1A the cue solutions were aqueous odors experienced retronasally $(\mathrm{A}=$ peppermint, $\mathrm{B}=$ almond $)$ while in Experiment $1 \mathrm{~B}$ the cue solutions were tastes $(\mathrm{A}=$ lemon, $\mathrm{B}=$ salt $)$. All groups were then tested for their preference for cue solution A over unflavored water in two-bottle tests. If flavor preference learning is susceptible to overshadowing then the preference for flavor A relative to water in Group Overshadow will be attenuated compared to Group Paired-Control.

In Experiment 1C all groups received peppermint and almond cue solutions in simultaneous compound with maltodextrin: in

\footnotetext{
${ }^{1}$ In the experiment described here the tastes were moderately preferred to the odors. In a second experiment, in which the odors were moderately preferred to the tastes, Capaldi and Privitera (2008) observed potentiation of the disliked tastes by odors.
} 
Table 1

Design of Experiments $1 A, 1 B$, and $1 C$

\begin{tabular}{lll} 
& 1-Bottle train & 2-Bottle test \\
\hline Experiment 1A & & \\
$\quad$ Overshadow & $3 \times \mathrm{PA}+/ 3 \times \mathrm{W}$ & $2 \times \mathrm{P}-\mathrm{v} \mathrm{W}$ \\
Paired-Control & $3 \times \mathrm{P}+/ 3 \times \mathrm{W}$ & \\
$\quad$ Unpaired-Control & $3 \times \mathrm{W}+/ 3 \times \mathrm{P}-$ & \\
Experiment 1B & & $2 \times \mathrm{L}-\mathrm{v} \mathrm{W}$ \\
$\quad$ Overshadow & $3 \times \mathrm{LS}+/ 3 \times \mathrm{W}$ & \\
Paired-Control & $3 \times \mathrm{L}+/ 3 \times \mathrm{W}$ & \\
$\quad$ Unpaired-Control & $3 \times \mathrm{W}+/ 3 \times \mathrm{L}-$ & \\
Experiment 1C & & \\
Blocking & $3 \times \mathrm{A}+/ 3 \times \mathrm{AP}+$ & $2 \times \mathrm{P}-\mathrm{v} \mathrm{W}$ \\
$\quad$ Unpaired-Control & $3 \times \mathrm{A}-/ 3 \times \mathrm{AP}+$ & \\
$\quad$ Maltodextrin-Control & $3 \times \mathrm{W}+/ 3 \times \mathrm{AP}+$ & \\
$\quad$ Water-Control & $3 \times \mathrm{W} / 3 \times \mathrm{AP}+$ & \\
\hline
\end{tabular}

Note. $\mathrm{P}$ and $\mathrm{A}$ refer to peppermint and almond, $\mathrm{L}$ and $\mathrm{S}$ refer to lemon and salt, $\mathrm{W}$ refers to plain water, while + refers to $15 \%$ maltodextrin, and - refers to the absence of the maltodextrin reinforcer when a cue flavor was present.

Group Blocking this was accompanied by additional sessions during which almond was paired with maltodextrin alone; in Group Unpaired-Control almond was presented alone in the absence of maltodextrin; in Group Maltodextrin-Control the additional sessions consisted of access to unflavored maltodextrin; and in Group Water-Control the additional sessions were access to plain water. All groups were then tested for their preference for peppermint over unflavored water in two-bottle tests. The extent to which the preference for peppermint over water is attenuated in Group Blocking as compared to the three control conditions will provide a measure of whether prior training with almond will block learning about peppermint. If blocking is present then the preference for peppermint over water will be lower in Group Blocking than in all the control groups.

\section{Method}

\section{Subjects and Apparatus}

Twenty-four naïve male hooded Lister rats were used as the subjects in each of Experiments $1 \mathrm{~A}$ and $1 \mathrm{~B}$, and 32 rats were used in Experiment 1C. The rats in these experiments were supplied by Charles River Limited, Kent, United Kingdom. Rats weighed between 225 and $280 \mathrm{~g}$ at the start of the experiments and were housed in groups of four under a $12 \mathrm{hr} / 12 \mathrm{hr}$ light/dark cycle. Training and test sessions were run approximately $5 \mathrm{hr}$ into the dark portion of the cycle.

Training and testing took place in a separate experimental room that contained 12 white acrylic drinking boxes, $32 \times 15 \times 12 \mathrm{~cm}$, with smooth flat flooring of the same material as the walls and wire mesh lids. Two 50-ml drinking bottles, each with a metal spout, could be inserted $6 \mathrm{~cm}$ apart at one end of each box. Consumption was assessed by weighing the bottles before and after each session. The cue solutions used in Experiment 1A and $1 \mathrm{C}$ were $0.5 \%$ (vol/vol) peppermint and almond (Supercook, Sherburn-in-Elmet, Leeds, U.K.). The cue solutions used in Experiment $1 \mathrm{~B}$ were $3 \%$ (wt/vol) Sainsbury's pure lemon juice and $1 \%(\mathrm{wt} / \mathrm{vol})$ salt. Plain tap water was used to make all solutions.
The reinforcing solution for all of Experiments $1 \mathrm{~A}, 1 \mathrm{~B}$, and $1 \mathrm{C}$ was $15 \%$ (wt/vol) maltodextrin (C*Dry MD01904, Cerestar-U.K., Manchester, United Kingdom) which contains approximately $2 \%$ mono and disaccharides with the remainder being polysaccharides.

\section{Procedure}

\section{Experiment 1A}

Animals were placed on a schedule of food and water restriction that consisted of $1 \mathrm{hr}$ access to water and food per day. This $1 \mathrm{hr}$ access was given $1 \mathrm{hr}$ after that day's training session. To accustom the animals to the experimental apparatus they received two days of preliminary training, consisting of access to water for 10 min each day in the drinking boxes. Animals were then randomly assigned to three treatment groups - Overshadow, Paired-Control, and Unpaired-Control with eight animals per group.

All groups received three conditioning cycles. On the first day of each cycle they received access to $10 \mathrm{ml}$ of the maltodextrin solution presented in a single bottle. In Group Overshadow this solution was flavored with peppermint and almond, in Group Paired-Control it was flavored with peppermint, and in Group Unpaired-Control it remained unflavored. On the second day of each cycle all groups received access to a supplementary $10 \mathrm{ml}$ of water. In Groups Overshadow and Paired-Control this supplement was unflavored, in Group UnpairedControl it was flavored with peppermint. All sessions were $30 \mathrm{~min}$ long and the amount consumed was measured by weighing the bottle before and after each session. The bottles were always placed on the left of the cage during training.

The day after the third training cycle was a rest day in which animals remained in the home cage. All animals received a $10 \mathrm{~min}$ choice test on each of the next two days; each was between peppermint and unflavored water. The bottles were inserted simultaneously into the drinking box and the side containing the cue solution was reversed between the two tests.

\section{Experiment 1B}

The methods and stimuli used for Experiment 1B were the same as for Experiment $1 \mathrm{~A}$ with the exception of the following changes: lemon was used in the place of peppermint, salt was used in the place of almond, and $16 \mathrm{ml}$ of each solution was provided each day during training. In addition, the animals in Experiment $1 \mathrm{~B}$ received preexposure to the experimental context under a water deprivation procedure ( $1 \mathrm{hr}$ water per day) and were swapped to food deprivation $(1 \mathrm{hr}$ food per day) for the training and test phases of the experiment. During training, animals were allowed access to the solutions for either three hours or until the solution was completely consumed (whichever was the shorter). Test sessions were $10 \mathrm{~min}$ long as in Experiment 1A.

\section{Experiment 1C}

The pretraining methods and deprivation procedures used for Experiment $1 \mathrm{C}$ were the same as for Experiment 1A. Following pretraining animals were then randomly assigned to four treatment groups: Water-Control, Maltodextrin-Control, Unpaired-Control, and Blocking. All groups received three conditioning cycles, each consisting of two days of exposure to $10 \mathrm{ml}$ of fluid. On the first day of 
each cycle this fluid was water in Group Water-Control, unflavored $15 \%$ maltodextrin in Group Maltodextrin-Control, almond alone in Group Unpaired-Control, and 15\% maltodextrin flavored with almond in Group Blocking. On the second day of each cycle the fluid was a compound of almond, peppermint and $15 \%$ maltodextrin. Testing took place on the two days following the completion of training. All animals received two 10-min choice tests between peppermint and water each performed in the same manner as in Experiment $1 \mathrm{~A}$.

\section{Results}

\section{Experiment 1A}

All statistical tests reported here used a significance value of $p=$ .05 . Training consumption was analyzed as the amount of cue solution A (peppermint) against the amount consumed of the additional solution averaged across training (see Table 2). A two-way Analysis of Variance (ANOVA) revealed no significant effect of group, $F(2$, $21)=2.20, p=.136$, an effect of solution type, $F(1,21)=4.35, p=$ .049 , and a significant interaction between the two factors, $F(2,21)=$ 81.64, $p<.001$. Pairwise comparisons revealed that consumption of peppermint was lower in Group Unpaired-Control (the only group in which peppermint was not paired with maltodextrin) than in the other two groups, lowest $F(1,21)=138.06, p<.001$. Although the consumption of peppermint was numerically higher in Group Overshadow than Group Paired-Control this difference was not significant, $F(1,21)=3.56, p=.073$. Consumption of the additional solution was higher in Group Unpaired-Control (the only group for which the additional solution contained maltodextrin) than in the other two groups, lowest $F(1,21)=13.31, p=.002$. Although the consumption of the additional solution was numerically lower in Group Overshadow than Group Paired-Control this difference was not significant, lowest $F(1,21)=3.61, p=.071$.

The most important data from Experiment $1 \mathrm{~A}$ are the total consumption of peppermint and water by all groups across testing (Figure 1, Panel A). A two-way ANOVA of the consumption data

Table 2

Training Consumption From Experiments $1 A, 1 B$, and $1 C$

\begin{tabular}{lcc}
\hline Experiment 1A & Peppermint & Additional \\
Overshadow & $9.6(0.2)$ & $6.3(0.4)$ \\
Paired-Control & $9.0(0.2)$ & $7.3(0.5)$ \\
Unpaired-Control & $5.7(0.3)$ & $9.3(0.3)$ \\
\hline Experiment 1B & Lemon & Additional \\
Overshadow & $15.7(0.1)$ & $7.6(0.6)$ \\
Paired-Control & $15.4(0.1)$ & $7.6(1.3)$ \\
Unpaired-Control & $7.2(0.8)$ & $15.2(0.4)$ \\
\hline Experiment 1C & Peppermint & Additional \\
Blocking & $9.6(0.2)$ & $9.8(0.4)$ \\
Unpaired-Control & $9.3(0.4)$ & $5.9(0.6)$ \\
Maltodextrin-Control & $10.0(0.0)$ & $10.0(0.0)$ \\
Water-Control & $9.8(0.2)$ & $5.4(0.6)$ \\
\hline
\end{tabular}

Note. Shows mean consumption in grams (with SEM) averaged across training for each group. Peppermint and Lemon refer to consumption of the solutions containing these cues while Additional refers to the consumption during the remaining training sessions (see Table 1 and methods for Experiment $1 \mathrm{~A}-1 \mathrm{C}$ for details of the solutions given for each group). revealed that the effect of stimulus type (peppermint or water) approached statistical significance, $F(1,21)=4.21, p=.053$, there was a significant effect of group, $F(2,21)=5.26, p=.014$, and a significant interaction between the two factors, $F(1,21)=$ $68.33, p<.001$. Simple-effect analyses of the interaction revealed that, in both of Groups Overshadow and Paired-Control consumption of peppermint was higher than that of water $F(1,21)=5.20$, $p=.033$; and $F(1,21)=78.30, p<.001$, respectively, while in Group Unpaired-Control consumption of water was greater than that of peppermint, $F(1,21)=57.38, p<.001$. To further examine the effects of overshadowing the difference between consumption of water and peppermint during test was calculated. These differences were higher in Group Paired-Control than in Group Overshadow, $F(1,21)=21.58, p<.001$, indicating that overshadowing had occurred.

\section{Experiment 1B}

Training consumption was analyzed as the amount of cue solution A (lemon) against the amount consumed of the additional solution averaged across training (see Table 1). A two-way ANOVA revealed no significant effect of group, $F<1$, an effect of solution type, $F(1,21)=23.43, p<.001$, and a significant interaction between the two factors, $F(2,21)=93.72, p<.001$. Pairwise comparisons revealed that consumption of lemon was lower in Group Unpaired-Control (the only group in which lemon was not paired with maltodextrin) than in the other two groups [lowest $F(1,21)=142.52, p<.001$, while consumption of the additional solution was higher in Group Unpaired (the only group for which the supplementary solution contained maltodextrin) than in the other two groups, lowest $F(1,21)=39.38, p<.001$. Groups Overshadow and Paired-Control did not differ in either their consumption of peppermint or the supplementary solution $\left(F_{\mathrm{S}}<1\right)$.

The most important data from Experiment 1B are the total consumption of lemon and water by all groups across testing (Figure 1, Panel B). A two-way ANOVA of the consumption data revealed significant effects of stimulus type (lemon or water), $F(1$, $21)=74.31, p<.001$ and group, $F(2,21)=16.57, p<.001$, as well as a significant interaction between the two factors, $F(1$, $21)=22.35, p<.001$. Simple-effect analyses of the interaction revealed that, in both of Groups Overshadow and Paired-Control consumption of lemon was higher than that of water $[F(1,21)=$ $21.51, p<.001$ and $F(1,21)=97.32, p<.001$, respectively], while in Group Unpaired-Control consumption of water was no different to that of lemon, $F<1$. To further examine the effects of overshadowing the difference between consumption of water and lemon during test was calculated. These differences were higher in Group Paired-Control than it was in Group Overshadow, $F(1$, $21)=15.75, p=.001$, indicating that overshadowing had occurred.

\section{Experiment 1C}

Training consumption was split into consumption of the reinforced almond/peppermint compound on the second day of each training cycle, and consumption on the first day of each training cycle (see Table 1 for the nature of this additional solution). Both were subjected to a one-way ANOVA with a between-groups factor of treatment group. Unsurprisingly the analysis of consump- 

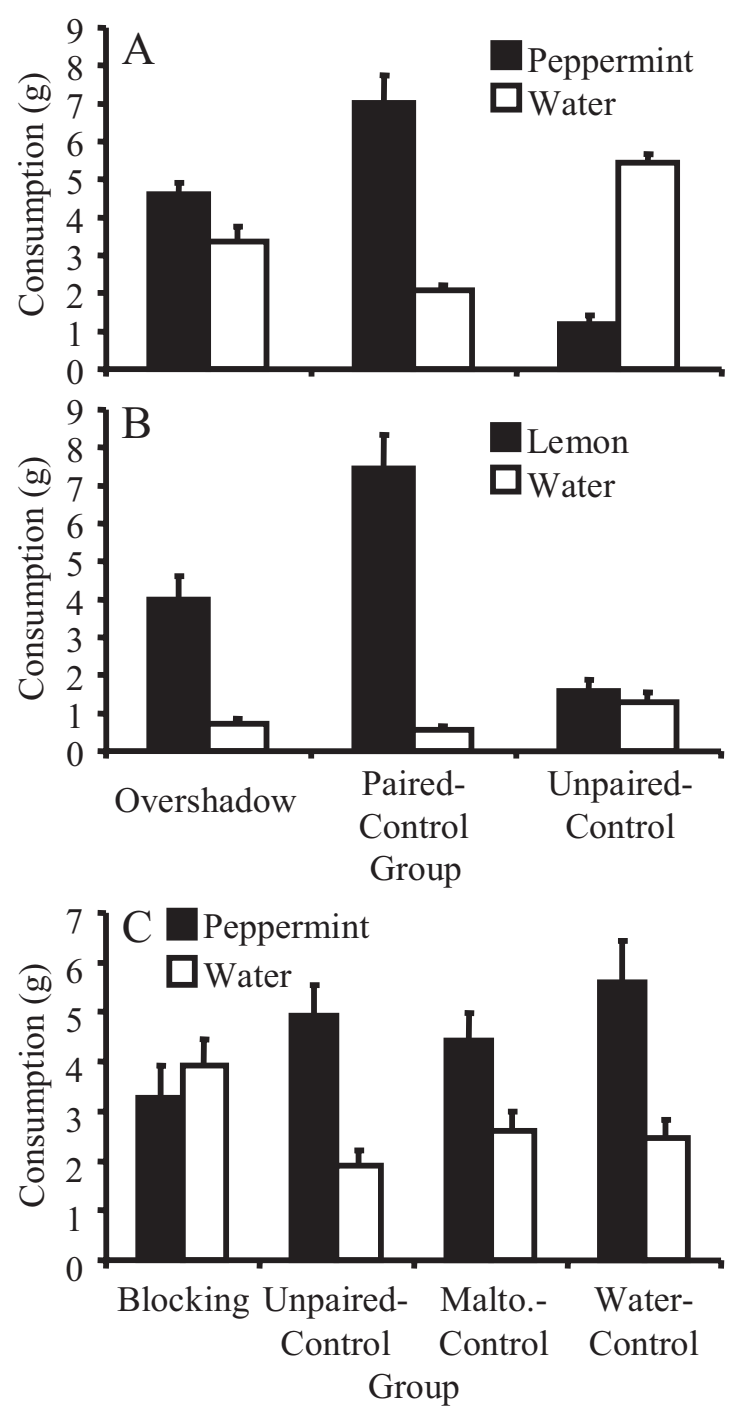

Figure 1. Panels $\mathrm{A}$ and $\mathrm{C}$ shows mean consumption (with SEM) of peppermint and water on test for each group in Experiments $1 \mathrm{~A}$ and $1 \mathrm{C}$ respectively. Panel B shows mean consumption (with $S E M$ ) of lemon and water on test for each group in Experiment 1B.

tion on the first day of each cycle showed an effect of treatment group, $F(3,28)=65.51, p<.001$. Inspection of Table 2 suggests that this was due to higher consumption in Groups MaltodextrinControl and Blocking where this session involved access to $15 \%$ maltodextrin than in the other groups when this was not the case. There was no effect of treatment group on consumption of the $\mathrm{AP}+$ compound during training, $F(3,28)=1.53, p=.230$.

The most important data from Experiment $1 \mathrm{C}$ are the total consumption of peppermint and water by all groups across testing (Figure 1, Panel C). A two-way ANOVA of the consumption data revealed the effect of stimulus type (peppermint or water) was significant, $F(1,28)=19.91, p<.001$, there was no significant effect of group, $F<1$, and a significant interaction between the two factors, $F(3,28)=4.23, p=.009$. Simple-effect analyses of the interaction revealed that in Group Blocking consumption of peppermint was no higher than that of water $F<1$, while in all the other three groups peppermint consumption was higher than that of water, lowest $F(1,28)=4.91, p=.035$. Critically, the difference between peppermint and water consumption was lower in Group Blocking than it was any other group, lowest $F(1,28)=4.56, p=$ .042 , and no other two groups differed significantly, highest $F(1$, 28) $=1.32, p=.261$.

\section{Summary of Experiments 1A-1C}

In both Experiments $1 \mathrm{~A}$ and $1 \mathrm{~B}$ the preference for a cue presented in simultaneous compound with maltodextrin was lower if that cue had been presented in combination with another cue during training than if it had been presented alone. This was true regardless of whether the cues were retronasally experienced odors (peppermint and almond in Experiment 1A) or tastes (lemon and salt in Experiment 1B). In contrast to the results of the experiments reported by Holder (1991) and Capaldi and Privitera (2008) these experiments show a clear overshadowing effect in flavor preference learning. It was noted in the Introduction that the only previous demonstration of overshadowing of flavor preference learning, reported by Capaldi and Hunter (1994), could have been a consequence of greater consumption during training in their control than their overshadowing group carrying-over to the test. It is difficult to apply the same analysis to the current results for there was no indication during training of a difference between Group Overshadowing and Group Paired-Control in their consumption of the solution that contained either peppermint (Experiment 1A) or lemon (Experiment 1B). In Experiment 1C the preference for a cue that had been presented in simultaneous compound with both maltodextrin and a second cue was lower if that second cue was also presented in compound with maltodextrin in separate sessions than if it has not. Thus this experiment shows clear evidence of blocking using similar procedures to those used to show overshadowing in Experiment 1A. This contrasts to previous studies by Holder (1991) and by Capaldi and Hunter (1994) that reported dissociations between overshadowing and blocking. It is not immediately obvious why the current experiments have produced results that stand in contrast to previous studies of cue-competition in flavor preference learning, but to avoid undue repetition we will postpone our analysis of this issue until the results of Experiments $2 \mathrm{~A}-2 \mathrm{C}$ are reported.

\section{Experiments 2A, 2B, \& 2C}

The purpose of Experiments 2A and 2B was to provide withinsubjects demonstrations of overshadowing of flavor preference learning (see Table 3 for the designs of Experiments 2A and 2B). For Experiment 2A rats drank solutions $\mathrm{AB}, \mathrm{C}$ and $\mathrm{D}$. Solutions $\mathrm{AB}$ and $\mathrm{C}$ were mixed with $8 \%$ maltodextrin $(\mathrm{AB}+, \mathrm{C}+)$, solution $\mathrm{D}$ was mixed with $0.1 \%$ saccharin $(\mathrm{D}-)$. In a first two-bottle test, the preference for $B$ over $C$ was assessed. If training with the $A B$ compound resulted in $\mathrm{A}$ overshadowing $\mathrm{B}$, then consumption of $\mathrm{C}$ should be greater than of B. In a second two-bottle test, the preference of A over D was assessed to examine if A had acquired any conditioned flavor preference relative to D, which itself had never been paired with maltodextrin. Although these results would be consistent with an analysis in terms of overshadowing, it is also the case that B is presented at test, for the first time, in the absence of the stimulus with which was trained, A. Consequently, a pref- 
Table 3

Design of Experiments $2 A, 2 B$, and $2 C$

\begin{tabular}{lcll}
\hline & Stage 1 (1-bottle) & \multicolumn{1}{c}{ Stage 2 (1-bottle) } & \multicolumn{1}{c}{ Test (2-bottles) } \\
\hline Experiment 2A & - & $4 \times \mathrm{AB}+/ \mathrm{C}+/ \mathrm{D}-$ & $2 \times \mathrm{B}-\mathrm{vs} \mathrm{C}-$ then $2 \times \mathrm{A}-\mathrm{vs} \mathrm{D}-$ \\
Experiment 2B & - & $6 \times \mathrm{AB}+/ \mathrm{CD}+/ \mathrm{D}-$ & $2 \times \mathrm{B}-\mathrm{vs} \mathrm{C}-$ \\
Experiment 2C & $4 \times \mathrm{A}+/ \mathrm{B}-$ & $1 \times \mathrm{A}+/ \mathrm{B}-, 2 \times \mathrm{AC}+/ \mathrm{BD}+$ & $2 \times \mathrm{C}-\mathrm{vs} \mathrm{D}-$ \\
\hline
\end{tabular}

Note. A to D represent different Kool Aid flavors. In Experiment $2 \mathrm{~A}+$ refers to $8 \%$ maltodextrin and - to $0.1 \%$ saccharin. In Experiments $2 \mathrm{~B}$ and $2 \mathrm{C}+$ refers to $16 \%$ maltodextrin and - to $2 \%$ maltodextrin.

erence for $\mathrm{C}$ over $\mathrm{B}$ could be based upon a neophobic reaction to B. Experiment $2 \mathrm{~B}$ was designed to overcome this shortcoming. For Experiment 2B, rats drank solutions $\mathrm{AB}, \mathrm{CD}$ and D. Solutions AD and $\mathrm{CD}$ were mixed with $16 \%$ maltodextrin $(\mathrm{AD}+, \mathrm{CD}+)$, while $\mathrm{D}$ was mixed with $2 \%$ maltodextrin $(\mathrm{D}-)$. According to standard models of conditioning (e.g., Pearce, 1987, 1994; Rescorla \& Wagner, 1972) nonreinforcement of D should protect C from overshadowing. Consequently, in a two-bottle test, in which consumption of $\mathrm{B}$ is assessed against $\mathrm{C}$, rats should consume more of C. This assessment of overshadowing also has the advantage of presenting, for the first time, $\mathrm{B}$ in the absence of $\mathrm{A}$, and $\mathrm{C}$ in the absence of D. Thus it is difficult to argue under these circumstances that differences in the consumption of $\mathrm{B}$ and $\mathrm{C}$ reflect differences in neophobia and thus this experiment assesses whether flavor preference overshadowing is modulated by the predictive status of the overshadowing CS.

The purpose of Experiment $2 \mathrm{C}$ was to provide a within-subjects demonstration of blocking of flavor preference learning (see Table 3 for the design of Experiments 2C). In stage 1 of this experiment rats consumed solutions A and B. Solution A was mixed with $16 \%$ maltodextrin $(\mathrm{A}+)$, and solution $\mathrm{B}$ was mixed with $2 \%$ maltodextrin $(\mathrm{B}-)$. In stage 2 , this training continued; in addition, rats consumed compounds $\mathrm{AC}$ and $\mathrm{BD}$, both of which were mixed with $16 \%$ maltodextrin $(\mathrm{AC}+, \mathrm{BD}+)$. In a final two-bottle test, the preference for $\mathrm{D}$ over $\mathrm{C}$ was assessed. $\mathrm{A}+$ training in stage 1 should blocking learning about $\mathrm{C}$ during the subsequent $\mathrm{AC}+$ trials, however, $\mathrm{B}-$ training in stage 1 should allow conditioning to proceed to D in stage 2. Consequently, in the test stage consumption of $\mathrm{D}$ should be higher than of $\mathrm{C}$.

In order to find the four, equally preferred, stimuli needed for these within-subject designs and to increase the generality of the investigation of overshadowing in flavor preference learning, Kool Aid flavors were used as the CSs in these experiments.

\section{Method}

\section{Subjects and Apparatus}

Sixteen, 24, and 32 male hooded Lister rats supplied by OLAC, Bicester, U.K. were used in Experiment 2A, 2B, and 2C, respectively. The animals in Experiment 2A were naïve, while animals in Experiments $2 \mathrm{~B}$ and $2 \mathrm{C}$ had previously taken part in an experiment with auditory stimuli, conducted in apparatus different to that used here. All were housed in pairs under a $12 \mathrm{hr} / 12 \mathrm{hr}$ light/dark cycle and had free feeding weights in the range 217-249 g (Experiment 2A), 335-415 g (Experiments 2B) and 385-590 g (Experiment 2C) at the start of the experiment. Training and test sessions were run approximately $5 \mathrm{hr}$ into the light portion of the cycle. Prior to training the rats were placed on a restricted feeding schedule and their weight was allowed to drop to between 85 and $90 \%$ of their free-feeding weights over a period of 7 days. During training and testing the rats' food ration was adjusted to maintain their weights between these limits. This food ration was given in the home cages $1 \mathrm{hr}$ after the daily experimental session had been completed and water was available ad libitum in the home cages.

For Experiment $2 \mathrm{~A}$, training and testing took place in a room that contained 16 custom-made drinking chambers measuring $32 \times 15 \times 12 \mathrm{~cm}$, with steel mesh flooring, white acrylic walls, and wire mesh lids. Two 50-ml drinking bottles with metal spouts could be inserted $8 \mathrm{~cm}$ apart at one end of each box. Consumption was assessed by weighing the bottles before and after each session. Four Kool Aid flavors (grape, cherry, tangerine and strawberry, Kraft Foods U.S.A., Rye Brook, NY) made with de-ionized water (at $0.05 \% \mathrm{wt} / \mathrm{vol}$ ), were used as the CSs. During training CS+ flavors were presented in simultaneous compound with $(8 \% \mathrm{wt} /$ vol) maltodextrin. All flavors were presented in compound with $0.1 \%$ (wt/vol) saccharin during training and test. The assignment of Kool Aid flavors to CSs was counterbalanced in the following fashion: for half of the animals the A/D flavors were grape and cherry and the $\mathrm{B} / \mathrm{C}$ flavors were tangerine and strawberry (the remaining animals received the opposite assignment of flavors to the $A / D$ and $B / C$ pairs). Within these counterbalance groups half of the animals received grape or tangerine as $\mathrm{A}$ or $\mathrm{B}$ and the other half received cherry and strawberry as A or B.

For Experiments $2 \mathrm{~B}$ and $2 \mathrm{C}$, experimental sessions were conducted in empty cages that were identical to those used for housing, and situated in the same room. Each cage measured $41 \times$ $25 \times 20 \mathrm{~cm}$ high, and had an empty food hopper at one end of the cage which measured $11.5 \mathrm{~cm}$ deep and $13.5 \mathrm{~cm}$ high. The floor and lower walls of the cage were made of plastic; the upper walls, ceiling, and food hopper were made of wire. Two 50-ml bottles could be placed into the food hopper so that their spouts protruded into the cage. These were accessible by the rat and positioned 3.5 and $7.5 \mathrm{~cm}$ from one of the side walls of the cage. Four unsweetened Kool-Aid flavors were used as conditioned stimuli. These were cherry, grape, orange, and kiwi/watermelon. All Kool-Aid solutions were made with tap water at $0.05 \% \mathrm{wt} / \mathrm{vol}$. During conditioning, $\mathrm{CS}+$ flavors were presented in compound with $16 \%$ wt/vol maltodextrin (C*Dry MD01904, Cargill, Manchester, U.K.). CS - flavors and flavors presented during the final two test sessions were presented in compound with $2 \%$ maltodextrin. Half the rats received orange as flavor $\mathrm{A}$ and kiwi/watermelon as flavor $\mathrm{B}$, while the remaining rats received the reverse; within each of these counterbalancing groups, half the rats received cherry as 
flavor $\mathrm{C}$ and grape as flavor $\mathrm{D}$, and the remainder received grape as $\mathrm{C}$ and cherry as D.

\section{Procedure}

\section{Experiment 2A}

To accustom the animals to the experimental apparatus they received 4 days of preliminary training, consisting of access to $0.1 \%$ saccharin water for $20 \mathrm{~min}$ each day in the drinking boxes. Training consisted of four 3-day cycles. The first day of each cycle consisted of access to cues A and B in simultaneous compound with maltodextrin and saccharin. The second day was access to cue $\mathrm{C}$ in simultaneous compound with maltodextrin and saccharin. The third day was access to cue D in simultaneous compound with saccharin alone.

The day after the fourth training cycle was a rest day in which animals remained in the home cage. All animals received a $20 \mathrm{~min}$ choice test on each of the next 4 days; Tests 1 and 2 were between $\mathrm{B}$ and $\mathrm{C}$ while Tests 3 and 4 were between A and D. During tests the bottles were inserted simultaneously into the drinking box and the position of the cue solutions was reversed between the two tests with those solutions. During test all solutions were presented in simultaneous compound with saccharin. Bottles were weighed before and after the session to measure consumption.

\section{Experiment 2B}

Training consisted of six 3-day cycles. During each cycle, rats received one session with each of the three training solutions: $\mathrm{AB}+, \mathrm{CD}+$, and $\mathrm{D}-$. The order of sessions within each cycle was pseudorandom, with the constraint that half the rats received $\mathrm{AB}+$ on the final session and the remainder received $\mathrm{CD}+$. This counterbalancing was orthogonal to the assignment of stimuli. For each session, every rat was placed into a separate cage and allowed access to a bottle containing $20 \mathrm{ml}$ of solution for $20 \mathrm{~min}$. For half the sessions the bottle was placed in the hopper in the position nearest the wall, while it was placed in the position furthest from the wall for the other sessions. The position of the bottle alternated throughout training.

Following this training stage, two more sessions were carried out in which rats were placed into the cages and two bottles presented. One bottle contained B - and the other C-, with $40 \mathrm{ml}$ of solution in each bottle. On the first test day half the rats received $\mathrm{B}-$ in the bottle nearest the wall and $\mathrm{C}-$ in the other, with the remaining rats receiving the opposite arrangement. These positions were reversed for all rats for the second test day. Rats were allowed $60 \mathrm{~min}$ access to the bottles.

\section{Experiment 2C}

Training consisted of two stages. The first training stage contained eight sessions. Rats received presentation of $\mathrm{A}+$ during four of these sessions and $\mathrm{B}-$ during the remaining four; these sessions occurred in a double-alternating sequence, with half the rats receiving $\mathrm{A}+$ on the first session and $\mathrm{B}-$ on the final session and the other rats receiving the reverse of this sequence. This counterbalancing was orthogonal to the assignment of flavor stimuli. The second training stage consisted of six sessions: two sessions each with $\mathrm{AC}+$ and $\mathrm{BD}+$ and one session each with $\mathrm{A}+$ and $\mathrm{B}-$. Half the rats received these sessions in the sequence $\mathrm{AC}+, \mathrm{BD}+, \mathrm{A}+$, $\mathrm{B}-, \mathrm{AC}+, \mathrm{BD}+$; the remaining rats received the reverse, and this counterbalancing was orthogonal to both the sequencing of the previous stage and the assignment of flavors.

Following training, rats were given two test sessions. Two bottles were simultaneously presented for each session, with $40 \mathrm{ml}$ of solution in each. One bottle contained flavor $\mathrm{C}$ and the other contained $\mathrm{D}$, the positions of which were counterbalanced and changed between the two test sessions.

\section{Results}

\section{Experiment 2A}

Training consumption was averaged across sessions (see Table 4) and analyzed with a one-way ANOVA. There was a significant effect of stimulus type, $F(2,30)=191.82, p<.001, M S E=0.63$. Consumption of $\mathrm{D}-$ was lower than that of either $\mathrm{AB}+$ or $\mathrm{C}+$, lowest $F(1,15)=195.16, p<.001, M S E s>1.75$, although the difference in consumption between $\mathrm{AB}+$ and $\mathrm{C}+$ was numerically small, it was statistically significant, $F(1,15)=22.53, p<.001$, $M S E=0.06$.

The most important data from Experiment $2 \mathrm{~A}$ are from the consumption of $\mathrm{B}$ and $\mathrm{C}$ and of $\mathrm{A}$ and $\mathrm{D}$ averaged across testing (Figure 2, Panel A). Consistent with an overshadowing effect animals consumed more of $\mathrm{C}$ than of $\mathrm{B}, t(15)=3.86, p=.002, S E D$ (standard error of the difference) $=1.64$. In addition, A was consumed in preference to $\mathrm{D}, t(15)=9.36, p<.001, S E D=0.77$. The preference for $\mathrm{A}$ over $\mathrm{D}$ is important as it demonstrates that the rats can generalize a conditioned flavor preference established to a compound to a

Table 4

Training Consumption From Experiments $2 A, 2 B$, and $2 C$

\begin{tabular}{lcccc}
\hline Experiment 2A & $\mathrm{AB}+$ & $\mathrm{C}+$ & $\mathrm{D}-$ \\
& $9.7(0.1)$ & $9.4(0.1)$ & $4.8(0.4)$ & \\
Experiment 2B & $\mathrm{AB}+$ & $\mathrm{CD}+$ & $\mathrm{D}-$ & \\
& $11.4(0.4)$ & $11.2(0.4)$ & $7.9(0.4)$ & \\
Experiment 2C & $\mathrm{A}+$ & $\mathrm{B}-$ & & \\
Stage 1 Training & $13.8(0.4)$ & $8.6(0.6)$ & $\mathrm{AC}+$ & $\mathrm{BD}+$ \\
Experiment 2C & $\mathrm{A}+$ & $\mathrm{B}-$ & $16.6(0.4)$ & $15.9(0.4)$ \\
Stage 2 Training & $17.2(0.5)$ & $8.8(0.7)$ & \\
\hline
\end{tabular}

Note. Shows mean consumption in grams (with SEM) averaged across training. A to D represent different Kool Aid flavors. In Experiment $2 \mathrm{~A}+$ refers to $8 \%$ maltodextrin and - to $0.1 \%$ saccharin. In Experiments $2 \mathrm{~B}$ and $2 \mathrm{C}+$ refers to $16 \%$ maltodextrin and - to $2 \%$ maltodextrin. 

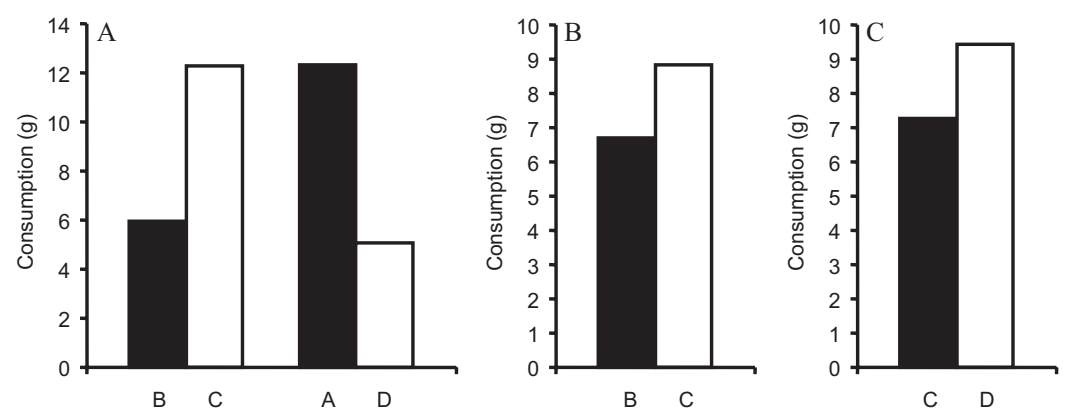

Figure 2. Panel A shows test data from Experiment 2A: The left of the panel shows mean consumption of the overshadowed (CS B) and control (CS C) solutions. The right of the panel mean consumption of the overshadowing (CS A) and unpaired (CS D) solutions. Panel B shows test data from Experiment 2B: mean consumption of the overshadowed (CS B) and control (CS C) solutions. Panel C shows test data from Experiment 2C: mean consumption of the blocked (CS C) and control (CS D) solutions.

test with one of the elements of that compound presented alone. Consequently, the preference for $\mathrm{C}$ over $\mathrm{B}$ is unlikely to be due to a complete failure to generalize between $\mathrm{B}$ presented alone on test and $\mathrm{B}$ presented as part of the reinforced $\mathrm{AB}$ compound during training. Thus the results of Experiment 2A, using a within-subjects design, complement those from Experiments $1 \mathrm{~A}$ and $1 \mathrm{~B}$, which used between-subjects designs and different CSs.

\section{Experiment 2B}

Table 4 shows mean consumption of each solution during training, averaged across sessions. A one-way ANOVA of these data showed that there was a significant effect of stimulus type, $F(2$, 46) $=55.66, p<.001, M S E=1.92$, Consumption of D - was lower than that of either $\mathrm{AB}+$ or $\mathrm{CD}+$, lowest $F(1,23)=54.14$, $p<.001$, MSEs $>3.29$, while consumption of $\mathrm{AB}+$ and $\mathrm{CD}+$ were equivalent, $F(1,23)<1, p=.474, M S E=1.97$.

The most important data from Experiment $2 \mathrm{~B}$ are the consumption of $\mathrm{B}$ and $\mathrm{C}$ averaged across testing (Figure 2B). Rats drank significantly more of $\mathrm{C}$ than $\mathrm{B}, t(23)=2.53, p=.019, S E D=$ 1.55. These results are consistent with an overshadowing effect, and thus complement the findings of Experiments 1A, 1B, and 2A. In Experiment 2B, however, both flavors $\mathrm{B}$ and $\mathrm{C}$ were presented alone for the first time at test. Consequently, any neophobia to the singly presented stimuli should have been equivalent.

\section{Experiment 2C}

Consumption during both stages 1 and 2 of training is shown in Table 4. Consumption of A and B differed in both of stages 1 and 2, $t(31)=10.10, p<.001, S E D=0.66$ and $t(31=10.69, p<.001$, $S E D=0.85$, respectively). Consumption of AC and BD did not differ in stage $2, t(31)=1.36, p=.19, S E D=0.57$. The most important data from this experiment are the consumption of $\mathrm{C}$ and $\mathrm{D}$ averaged across testing (Figure 2, Panel C). Consumption of D was significantly higher than that of $\mathrm{C}, t(31)=2.34, p=.026, S E D=0.92$, indicating a blocking effect. Thus the results of Experiment $2 \mathrm{C}$, using a within-subjects design, complement those from Experiment 1C, which used a between subjects design and different CSs.

\section{Discussion - Experiments 1 and 2}

Six experiments investigated whether flavor preference learning is susceptible to overshadowing and blocking. In Experiment $1 \mathrm{~A}$ animals in Group Overshadow were given paired presentations of peppermint and almond odors with maltodextrin. In two-bottle tests peppermint was presented alongside water; rats in Group Overshadow showed a weaker preference for peppermint, relative to a Group Paired-Control who were given identical training, with the exception that the almond odor was not presented during training. The generality of this result was extended in Experiment $1 \mathrm{~B}$, in which the odors of peppermint and almond used in Experiment $1 \mathrm{~A}$ were replaced with the tastes lemon and salt. Experiments $2 \mathrm{~A}$ and $2 \mathrm{~B}$ replicated these effects using within-subjects designs and further controls to limit the potential effects of neophobia. In Experiment $1 \mathrm{C}$ animals in Group Blocking received a compound of almond and peppermint paired with maltodextrin after prior pairings of almond and maltodextrin while controls received the same almond/peppermint compound training but without prior almond/maltodextrin pairings. Rats in Group Blocking showed a weaker preference for peppermint than did animals in the control groups. Experiment $2 \mathrm{C}$ extended this observation of blocking to a within-subject design. Overall the results provide a series of clear demonstrations of both overshadowing and blocking of flavor preference learning which contrasts to previous inconsistent reports of cue-competition effects in this preparation. This raises the obvious question of why cue-competition is present in some circumstances and not others. We will begin to answer this question by focusing on overshadowing because the analysis we have developed of overshadowing suggests an account of why blocking is, perhaps, more consistently observed.

As noted in the introduction, Holder (1991) failed to observe overshadowing while Capaldi and Privitera (2008) demonstrated the opposite effect-potentiation. One potential differentiating factor between these studies and those reported here is that we presented compounds to subjects that comprised elements which were drawn from the same sensory modality, while the experiments reported by Capaldi and Privitera and by Holder all employed a multimodal compound that comprised an odor and a taste. It is possible, therefore, that overshadowing is more likely to occur when the compound comprises elements that are drawn from the same sensory modality, but that overshadowing is attenuated, or possibly reversed to potentiation, when the elements of the compound are drawn from different sensory modalities. An alternative possibility is suggested by the fact that the stimuli in the current 
experiments were either counterbalanced or, on the basis of prior experiments that we have conducted, support a similar level of conditioning when presented alone (e.g., Dwyer, 2000; Dwyer, Mackintosh, \& Boakes, 1998; Dwyer, Pincham, Thein, \& Harris, 2009). It seems reasonable to conclude, therefore, that these stimuli were of equivalent salience. In contrast, the stimuli used by, for example, Capaldi and Privitera, had very different saliencies. It is thus possible that overshadowing may be more probable when stimuli are of roughly equal salience but that potentiation is more likely when stimuli are greatly different in salience.

From the experiments reported here, it is difficult to be certain whether differences in salience or differences in stimulus modality are the critical factor in separating our results from those reported previously. That said, we have two reasons for suspecting that having a compound that comprises elements of the same or different modalities is relatively unimportant. First, Experiments 2A and 2B both used Kool-Aid flavors as cues A and B in an AB compound. These flavors comprise both a taste and an odor; thus, whatever tendency for overshadowing that may have been promoted by the sensory components that A and B have in common, should have been nullified by the tendency for potentiation that would have been promoted by the sensory components that A and B differ upon. Second, studies of the effects of compound conditioning in flavor aversion studies have revealed that not only can a taste potentiate learning about an odor (e.g., Rusiniak, Hankins, Garcia, \& Brett, 1979), and that an odor can potentiate learning about a taste (e.g., Slotnick, Westbrook, \& Darling, 1997), but also that a taste can potentiate learning about another taste (e.g., Bouton, Dunlap, \& Swartzentruber, 1987). If the properties of compound conditioning in flavor preference learning bear even some similarity to the properties of compound conditioning in flavor aversion learning, then these studies cast doubt upon the influence of sensory modality on overshadowing and/or potentiation of flavor preference learning.

As the preceding discussion has hinted, variations in the effect of compound conditioning on flavor preference learning suggest that two antagonistic mechanisms exist: one of which supports the overshadowing of a target CS by another CS, the other supports the potentiation of the target CS by another CS. The first mechanism may have as its basis any model of associative learning which restricts the strength of the association between a target CS and a US when the target is conditioned in compound with another CS (e.g., Mackintosh, 1975; Pearce \& Hall, 1980; Rescorla \& Wagner, 1972). The second mechanism may have as its basis a model which explains potentiation in terms of the formation of within-compound associations (e.g., Durlach \& Rescorla, 1980). According to this idea, pairing a compound of $\mathrm{AB}$ with a US results in the formation of associations between these stimuli and the US, plus reciprocal associations between A and $\mathrm{B}$. One consequence of this is that B may come to evoke considerable conditioned responding by virtue of the indirect association that $\mathrm{B}$ has with the US via a within-compound association with A (as well as its direct association with the US). If the sum of these direct and indirect associations is greater than the associative strength acquired by an element conditioned in isolation then potentiation will be evident. Therefore, to account for the discrepancy between the current results and those reported by Capaldi and Privitera (2008) and by Holder (1991), one could propose that within-compound associations were of a negligible strength in the current experiments, whereas they were sufficiently strong between the taste and odor in the experiment by Holder to exactly offset overshadowing, and so strong in the experi- ments reported by Capaldi and Privitera that potentiation was revealed. However, it is not immediately obvious why this might be the case. We have already noted that the stimuli that were presented as compounds in our current experiments were of similar salience and drawn from the same sensory modality. On the basis of experiments reported by Rescorla \& Furrow (2007; see also: Grand, Close, Hale, \& Honey, 2007; Rescorla \& Gillan, 1980)—who demonstrated that stimulus similarity promoted the formation of associations-one might expect the formation of more pronounced within-compound associations between the, presumably, more similar stimuli used in the current experiments than the less similar stimuli used in the experiments by Capaldi and Privitera, and by Holder. Furthermore, studies of flavor-aversion learning imply that the within-compound association analysis of potentiation may be incomplete. Durlach and Rescorla (1980) showed that the aversion to an odor that is normally potentiated by pairing an odor/taste compound with illness can be weakened by extinction of the taste CS. However, the same studies did not show that when the taste was nonreinforced, an underlying overshadowing effect was revealed - only that potentiation was abolished. In addition, Schnelker and Batsell (2006) have provided evidence for the presence of a within-compound association between an odor and a taste following conditioning of an odor/taste compound with illness, but under circumstances in which potentiation was not observed. It therefore remains to be determined whether differences in the impact of within-compound associations can account for variations in the effect of compound conditioning in general and in flavor preference learning in particular.

\section{A Configural Analysis of Flavor Preference Learning}

Rescorla (1981; Rescorla \& Durlach, 1981), provided an alternative account of the effect on learning of compound stimulus presentation-in particular from studies that have examined learning about flavors. Instead of analyzing a compound into its constituent elements and then reassociating them, he suggested that the organism may, by default, encode a compound as a unitary configuration which enters into an association with the US as a whole (see also: Pearce, 1987, 1994). This notion has been adopted by Trost and Batsell (2004; see also: Batsell \& Paschall, 2009; Kucharski \& Spear, 1985 ) to account for the potentiation of odor conditioning by tastes in flavor aversion conditioning procedures. According to this analysis, a configuration composed of two stimuli is more salient than either of the stimuli alone (see also: Hull, 1949; Pearce, 2002); conditioning with a compound will therefore proceed more readily than conditioning to the stimuli trained in isolation. The magnitude of conditioned responding to the elements of a compound, at test, will then be determined by the extent to which the associative strength of the configuration generalizes to these elements. If this generalization is substantial, then conditioned responding will be stronger than following simple elemental training (i.e., a potentiation effect). If, however, this generalization is slight, then the conditioned response to the elements following compound training will be weaker than following elemental training (i.e., an overshadowing effect). This analysis can be applied to the current discussion of the effects of compound conditioning on flavor preference learning. For the current experiments, the generalization of associative strength from the training compounds to the elements may have been relatively weak, resulting in a similarly weak preference for these flavors and hence an overshadowing effect. For the experi- 
ments reported by Capaldi and Privitera (2008) and Holder (1991), however, this generalization may have been more substantial, resulting in a more substantial preference.

\section{A Modified Version of Pearce's (1987) Model}

The notions outlined in the preceding paragraph can be presented in a more formal manner by taking a popular model of configural conditioning (Pearce, 1987) and adapting it to take account of the idea that (1) conditioning to compounds proceeds more readily than to single stimuli and that (2) generalization is variable. The change in the strength of the excitatory association between configuration $\mathrm{X}\left(\Delta \mathrm{V}_{\mathrm{x}}\right)$ and the US is given by equation 1 :

$$
\Delta \mathrm{V}_{\mathrm{x}}=\Sigma \alpha \cdot \beta \cdot\left(\lambda-\overline{\mathrm{E}}_{\mathrm{x}}\right)
$$

where the novel $\Sigma \alpha$ parameter is the sum of the saliencies of the elements present in the configuration, $\beta$ is a learning rate parameter determined by the US and $\lambda$ is the asymptote of conditioning supported by the US. $\overline{\mathrm{E}}_{\mathrm{x}}$ is the net associative strength of the configuration for that trial, determines the strength of conditioned responding, and is given by equation 2 :

$$
\overline{\mathrm{E}}_{\mathrm{x}}=\mathrm{E}_{\mathrm{x}}+\mathrm{e}_{\mathrm{x}}
$$

$E_{x}$ is the current associative strength of configuration $X, e_{x}$ is the associative strength that generalizes to configuration $\mathrm{X}$ from similar configurations and is simply the sum of the associative strengths of all other configurations multiplied by their similarity to X (Pearce, 1987, p. 65-67). Finally, the similarity of $X$ to other configurations $\left({ }_{x} S_{x},\right)$ is determined by Equation 3:

$$
{ }_{\mathrm{x}} \mathrm{S}_{\mathrm{x}}=\frac{\mathrm{P}_{\mathrm{com}}^{\mathrm{G}}}{\mathrm{P}_{\Sigma \mathrm{X}} \cdot \mathrm{P}_{\Sigma \mathrm{X}}}
$$

Where $\mathrm{P}_{\mathrm{com}}^{\mathrm{G}}$ is the perceived intensity of the elements common to $X$ and $X^{\prime}$ raised to the power $G$ (which was set to 2 in Pearce, 1987). $\mathrm{P}_{\Sigma \mathrm{X}}$ and $\mathrm{P}_{\Sigma \mathrm{X}}$, refer, respectively, to the total perceived intensity of the stimulation on trials with $\mathrm{X}$ and $\mathrm{X}^{\prime}$. $\mathrm{G}$ is a parameter that determines the impact of the elements common to, for example, a training configuration and a test configuration. When its value is high, the influence of the common elements will be slight and the effects of generalization will be correspondingly small. When the value of $\mathrm{G}$ is relatively low, however, the influence of the common elements will be more substantial, as will also be the corresponding effects of generalization (for an alternative, but related, method of varying generalization between configurations see: Kinder \& Lachnit, 2003; Pearce, Esber, George, \& Haselgrove, 2008).

\section{An Application to Overshadowing and Potentiation}

The left panel of Figure 3 shows the results of a computer simulation of these equations for trials in which a compound of $\mathrm{AB}$ and an element, $\mathrm{C}$, were paired with a US (i.e., $\mathrm{AB}+, \mathrm{C}+$ ). On each simulated conditioning trial, the value of $\beta$ was 0.2 and $\lambda$ was 1 . The values of $\alpha$ for $\mathrm{A}, \mathrm{B}$, and $\mathrm{C}$ were all 0.1 (thus $\alpha_{\mathrm{AB}}=2 \alpha_{\mathrm{c}}$ ). The perceived intensity of an element was equal to its $\alpha$; and it was finally

$$
\mathrm{G}=2.00
$$

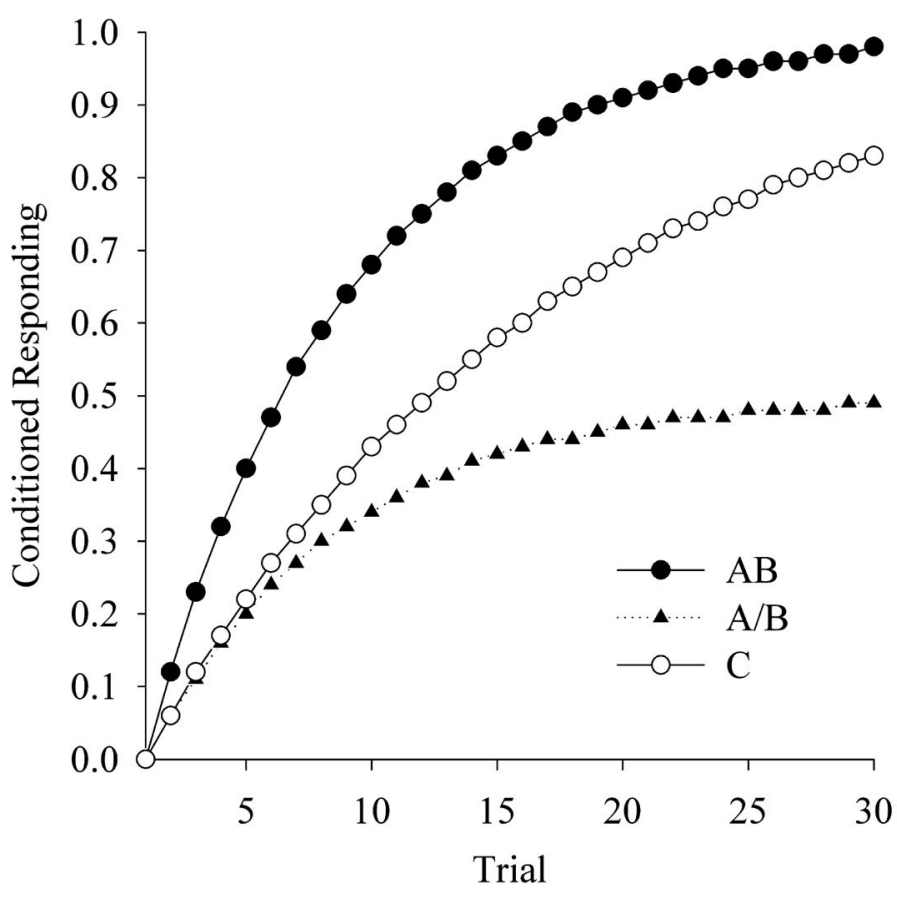

$\mathrm{G}=1.75$

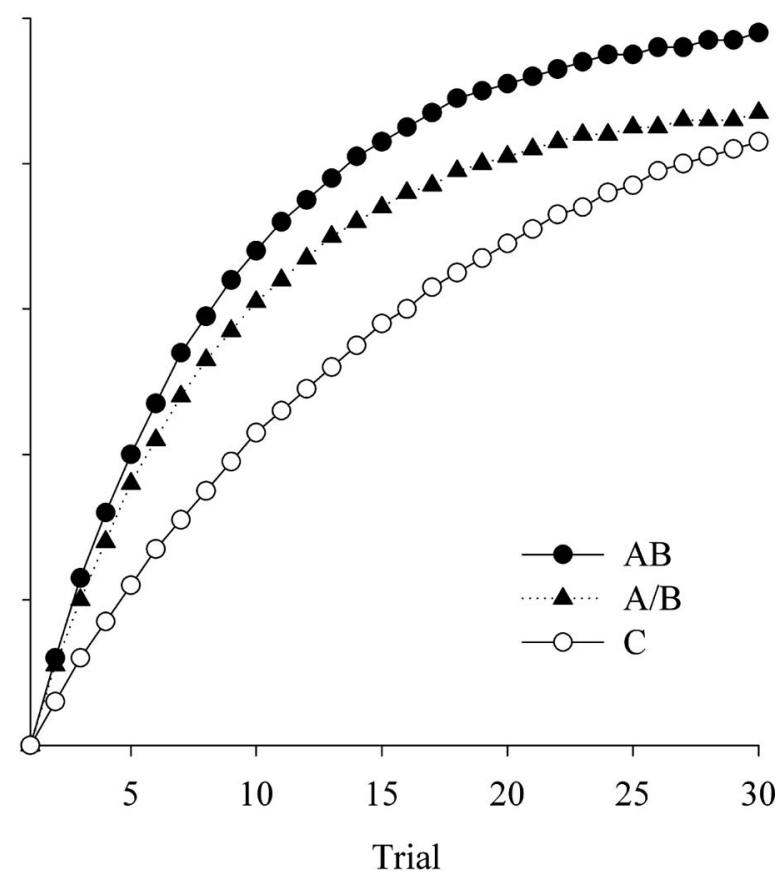

Figure 3. Simulations of $\mathrm{AB}+, \mathrm{C}+$ training with a modified configural theory. The course of acquisition to $\mathrm{AB}$ and $\mathrm{C}$, and the generalized conditioned responding that would be expected to $\mathrm{A}$ or $\mathrm{B}(\mathrm{A} / \mathrm{B})$ throughout the simulation. Left panel $\mathrm{G}=2$; Right Panel: $\mathrm{G}=1.75$. 
assumed, for this simulation, that the value of $G$ was 2.00. The left panel of Figure 3 shows that conditioning proceeds more rapidly to $\mathrm{AB}$ than to $\mathrm{C}$. Also plotted on this figure is the simulated associative strength of the elements A and B at each point of the simulation. Throughout the simulation, conditioned responding is predicted to be higher to $\mathrm{C}$ than to either $\mathrm{A}$ or $\mathrm{B}$. The right panel of Figure 3 shows the output of a second computer simulation that was identical in all respects to the previous simulation, with the exception that the value of $\mathrm{G}$ was set to 1.75 . Again, conditioning proceeds more readily to $\mathrm{AB}$ than to $\mathrm{C}$, but now, until the asymptote of conditioning is reached, conditioned responding is predicted to be more substantial to $\mathrm{A}$ and $\mathrm{B}$ than to $\mathrm{C}$. These simulations provide a potential resolution of the results of the current experiments and those reported by Capaldi and Privitera (2008) and Holder (1991). If it is assumed that for the current experiments, the generalization from the training compounds to the test element was relatively slight (see Figure 3, left panel) then overshadowing is anticipated. If it is assumed, however, that generalization from the training compounds to the test element was more substantial (see Figure 3, right panel), then prior to the asymptote of conditioning being reached, potentiation is anticipated (ala Capaldi and Privitera), and at asymptote neither overshadowing nor potentiation should be evident (ala Holder).

\section{An Application to Blocking}

The effect of varying the degree of generalization between configurations has rather less impact, however, on determining whether blocking will be apparent or not. If one assumes that generalization between configurations (that is to say generalization from $\mathrm{A}$ to $\mathrm{AB}$ during training, and from $A B$ to $B$ at test $)$ is relatively slight $(G=2)$ then blocking should be observed. $\mathrm{A}+, \mathrm{AB}+$ training should result in $\mathrm{B}$ having a net associative strength of $.25 \lambda$, whereas $\mathrm{AB}+$ training, in the absence of prior $\mathrm{A}+$ training, should result in $\mathrm{B}$ having a net associative strength of .5 $\lambda$. These predictions are, of course, entirely in line with the predictions of the original configural model proposed by Pearce (1987). It is interesting that if generalization between configurations is assumed to be more substantial $(G=1.75)$ then blocking will still be apparent and may even be enhanced relative to the low generalization case: Following $\mathrm{A}+\mathrm{AB}+$ training, $\mathrm{B}$ should have a net associative strength of $0.1 \lambda$, and following just $\mathrm{AB}+$ training, $\mathrm{B}$ should have a net associative strength of $.9 \lambda$. The model makes these predictions because $\mathrm{A}+$ training in stage 1 should result in $\mathrm{A}$ acquiring associative strength equal to $1 \lambda$. The associative strength of $A$ will almost completely generalize to the $\mathrm{AB}$ configuration during $\mathrm{AB}+$ training stage 2, precluding this configuration from gaining anything but the smallest amount of associative strength. Therefore, at test, the associative strength generalizing from $\mathrm{AB}$ to $\mathrm{B}$ will also be small. Conditioning $\mathrm{AB}$ in the absence of $\mathrm{A}+$ pretraining, will result in the $\mathrm{AB}$ configuration acquiring associative strength equal to $1 \lambda$, a substantial proportion of which will then generalize to B upon testing with this stimulus. These principles provide, again, a resolution of the current experiments and the experiments reported by Holder (1991). If it is assumed that generalization between configurations of flavor compounds used by Holder was substantial, then overshadowing may not be observed, but blocking will be preserved. However, if we assume that generalization between the flavor compounds used in the current experiments was more slight, then both overshadowing and blocking will be observed.

\section{Summary and Predictions}

It remains to be determined whether these assumptions can be fully justified. Capaldi and Hunter (1994) noted that conditioning of a taste/odor compound resulted in substantial generalization to the odor but not the taste when they were presented alone at test. They further noted that it is overly simplistic to account for their results in terms of differences in the salience of the taste or odor, but that rather taste/odor conditioning results in the formation of a configuration that is particularly similar to the odor element alone. Among other things, this proposal can explain the failure of Capaldi and Hunter (1994) to observe blocking of the odor by the taste because initial training to the taste would not generalize to the taste/odor compound sufficiently to reduce the error term for the compound. It can also explain the failure of the odor to block the taste because the failure to generalize between the odor/taste compound and the taste at test would mean that there was little or no conditioned response to the taste regardless of whether the odor had been paired with the US prior to compound training. The general idea that generalization between a compound and its elements is not a simple factor of the relative salience of the common and unique features is consistent with the idea that the " $G$ " parameter in Equation 3 may hold different values. The idea that generalization between a compound and either of its two elements might differ, despite those elements being equally salient, would require that either one element shared more features with the compound than the other or that the G parameter can vary as a function which element is being compared to the compound. Unfortunately, it is not possible to make a principled statement of whether either of these possibilities would be true in the case of the stimuli used by Capaldi and Hunter (1994).

In any case, this model does generate a number of testable predictions. First, with extended training, the effect of overshadowing should become more profound (Figure 3, left panel); however, it should be possible with extended training to abolish potentiation (Figure 3, right panel). The same prediction does not necessarily follow from a within-compound association analysis of potentiation. If anything, one might assume that extended training would increase the strength of the within-compound association and promote a more substantial potentiation effect. Second, while blocking should be observed regardless of the degree of generalization, the effects should be larger when generalization is higher (that is, blocking should be especially strong when overshadowing is weak). Third, it follows from the equations and principles described here that when the effect of generalization is assumed to be relatively slight (e.g., under the conditions favoring overshadowing), behavioral summation should not be observed but that when the effect of generalization is assumed to be more substantial (e.g., under the conditions favoring potentiation), behavioral summation should be present. This follows because the associative strength of a compound of two stimuli conditioned in isolation should, according to Equations 2 and 3, equal the associative strength of the elements of the compound at the conclusion of conditioning - if the generalization parameter $(\mathrm{G})=2-$ but be greater than the elements in isolation when $\mathrm{G}$ is less than 2 .

\section{Experiments 3A \& 3B}

Given that the model described above predicts that summation should not be observed in flavor preference learning when the stim- 
ulus parameters favor the observation of overshadowing, Experiment 3 examined summation with stimuli similar to those used in Experiments $2 \mathrm{~A}$ and $2 \mathrm{~B}$ where overshadowing was observed. The designs used in Experiments 3A and 3B are shown in Table 5 and represent adaptations of a typical summation design to allow for two-bottle tests of CS preference. In Experiment 3A, Group Individual received training with two $\mathrm{CS}+$ flavors $(\mathrm{A}$ and $\mathrm{C}$ ) and two $\mathrm{CS}$ - flavors (B and D) before being tested with both the elements alone (A vs. B and C vs. D) and in novel compounds (AC vs. BD). Summation would be observed if the preferences were higher in the compound test than in the element tests. But our model predicts that the nature of the test will not influence the degree of preference. Group Paired received training with $\mathrm{AC}+$ and $\mathrm{BD}-$ before the same tests. Here, a greater preference during the compound tests than the element tests is indicative of overshadowing. Thus this condition served as a test of whether the Kool Aid flavors used here as CSs interact as expected when presented as elements and compounds.

To anticipate the results of Experiment 3A, there was no evidence for summation but the size of the preference for the CS + flavors was particularly high which raised the possibility that ceiling effects might have obscured summation. Therefore in Experiment 3B the number of training trials was halved from the number used in Experiment $3 \mathrm{~A}$ to lower the CS + preference: animals in Group Individual now received two presentations of each of the individual CSs during training (see Table 5). In addition, Groups Individual and Paired from Experiment $3 \mathrm{~A}$ differed in the number of sessions of training they received. Therefore Experiment 3B used two different control conditions: Group Paired 4, which received four presentations of each compound CS (and thus received the same number of training sessions as Group Individual) and Group Paired 2, which received two presentations of each compound CS (and thus received the same number of exposures to each CS flavor as Group Individual).

\section{Method}

\section{Subjects and Apparatus}

Sixteen male hooded Lister rats supplied by OLAC, Bicester, U.K. were used in each experimental group for Experiments $3 \mathrm{~A}$ and $3 \mathrm{~B}$. The rats used in Experiment $3 \mathrm{~A}$ were naïve while those in Experiment $3 \mathrm{~B}$ had previously been used in an investigation of operant behavior that did not involve access to flavored foods other than unsweetened food pellets. All were housed in pairs under a $12 \mathrm{hr} / 12 \mathrm{hr}$ light/dark cycle and had free feeding weights in the range $349-420 \mathrm{~g}$ or $394-539 \mathrm{~g}$ at the start of the Experiments $3 \mathrm{~A}$ and $3 \mathrm{~B}$ respectively. The same food restriction schedule as described for Experiment $2 \mathrm{~A}$ was used.

Experiments $3 \mathrm{~A}$ and $3 \mathrm{~B}$ used the same equipment as described for Experiment 2A. Four Kool Aid flavors (grape, cherry, tamarind and strawberry) made with de-ionized water (at $0.05 \% \mathrm{wt} / \mathrm{vol}$ ), were used as the CSs. During training CS + flavors were presented in simultaneous compound with $(16 \% \mathrm{wt} / \mathrm{vol})$ maltodextrin (C*Dry MD 01904, Cerestar-U.K.). CS - flavors were presented in compound with $2 \%(\mathrm{wt} / \mathrm{vol})$ maltodextrin. During testing both $\mathrm{CS}+$ and $\mathrm{CS}-$ flavors (and their compounds) were presented in compound with $2 \%$ maltodextrin.

\section{Procedure}

\section{Experiment 3A}

All animals were habituated to the testing environment by being given access to $2 \%$ maltodextrin in 20 min sessions. No more than four pretraining sessions were required to establish reliable drinking. Preference training took place over 16 (Group Individual) or 8 (Group Paired) sessions with the start of training staggered so that both groups were tested together. Training sessions alternated between the CS+ and $\mathrm{CS}-$ (with half the animals receiving the $\mathrm{CS}+$ on the first day) and the position of the bottle on the left or right of the cage was varied on a double alternation schedule (LRRL for half of the animals and RLLR for the remainder). In Group Individual there were two $\mathrm{CS}+\mathrm{s}(\mathrm{A}$ and $\mathrm{C})$ and two $\mathrm{CS}-\mathrm{s}(\mathrm{B}$ and $\mathrm{D})$. The $\mathrm{CS}+\mathrm{s}$ and $\mathrm{CS}-\mathrm{s}$ were presented in alternation with the presentation of the $\mathrm{A} / \mathrm{B}$ and $\mathrm{C} / \mathrm{D}$ pairs intermixed (e.g., $\mathrm{A}+/ \mathrm{B}-/ \mathrm{C}+/$ $\mathrm{D}-/ \mathrm{A}+\ldots$. . Each $\mathrm{CS}$ was presented four times during training. For animals in Group Paired one compound $\mathrm{CS}+(\mathrm{AC}+)$ and one compound $\mathrm{CS}-(\mathrm{BD}-)$ were presented during training. As each of these compound CSs was presented four times during training animals in Group Paired received half as many training sessions as did those in Group Individual but the same number of exposures to each of the stimuli A-D.

Following training all animals received a 3-day test procedure. On each day there was a 20 min two-bottle test in which animals had free access to one $\mathrm{CS}+$ and one $\mathrm{CS}-$ (the side on which the $\mathrm{CS}+$ was

Table 5

Design of Experiments $3 A$ and $3 B$

\begin{tabular}{|c|c|c|c|}
\hline & 1-Bottle train & Element test & Compound test \\
\hline \multicolumn{4}{|c|}{ Experiment $3 \mathrm{~A}$} \\
\hline $\begin{array}{l}\text { Individual } \\
\text { Paired }\end{array}$ & $\begin{array}{l}4 \times \mathrm{A}+/ \mathrm{B}-/ \mathrm{C}+/ \mathrm{D}- \\
4 \times \mathrm{AC}+/ \mathrm{BD}-\end{array}$ & $A \vee B \& C \vee D$ & $A C \vee B D$ \\
\hline \multicolumn{4}{|c|}{ Experiment 3B } \\
\hline $\begin{array}{l}\text { Individual } \\
\text { Paired } 4 \\
\text { Paired } 2\end{array}$ & $\begin{array}{l}2 \times \mathrm{A}+/ \mathrm{B}-/ \mathrm{C}+/ \mathrm{D}- \\
4 \times \mathrm{AC}+/ \mathrm{BD}- \\
2 \times \mathrm{AC}+/ \mathrm{BD}-\end{array}$ & $A \vee B \& C \vee D$ & $A C \vee B D$ \\
\hline
\end{tabular}

Note. A, B, C, and D refer to different Kool Aid flavors and + refers to $16 \%$ maltodextrin and - to $2 \%$ maltodextrin which were presented in simultaneous compound with the relevant flavors during training. The order of Element and Compound tests was counterbalanced across animals and all CSs were presented in compound with $2 \%$ maltodextrin during test. When training was of different lengths across groups, the start of training was staggered so that all groups were tested at the same time. 
presented was the same across all tests but was counterbalanced across animals). There was one test with the CSs in compound (i.e., $\mathrm{AC}$ vs. BD) and two tests in which the CSs were tested as elements (i.e., A vs. B and C vs. D). Half of the animals received the compound test before the two element tests and the remainder received the two element tests before the compound test.

The assignment of Kool Aid flavors to CSs was counterbalanced in the following fashion: for half of the animals the A/B flavors were grape and cherry and the C/D flavors were tamarind and strawberry (the remaining animals received the opposite assignment of flavors to the $\mathrm{A} / \mathrm{B}$ and $\mathrm{C} / \mathrm{D}$ pairs). Within these counterbalance groups half of the animals received grape and tamarind as $\mathrm{CS}+\mathrm{s}$ and the other half received cherry and strawberry as $\mathrm{CS}+\mathrm{s}$. These assignments were the same in both Groups Individual and Paired.

\section{Experiment 3B}

The general methods of Experiment 3B were the same as in Experiment $3 \mathrm{~A}$ and only the differences are noted here. Rats in Group Individual received two presentations of each of the individual CS+ $\mathrm{s}(\mathrm{A}$ and $\mathrm{C})$ and two presentations of the $\mathrm{CS}-\mathrm{s}(\mathrm{B}$ and $\mathrm{D})$ during training. Rats in Group Paired 4 received four presentations of the compound $\mathrm{CS}+(\mathrm{AC}+)$ and the compound $\mathrm{CS}-(\mathrm{BD}-)$ during training. Rats in Group Paired 2 received two presentations of the compound $\mathrm{CS}+(\mathrm{AC}+)$ and the compound $\mathrm{CS}-(\mathrm{BD}-)$ during training. The test phase was the same as in Experiment 3A.

\section{Results}

\section{Experiment 3A}

The training data for Group Individual was averaged across all sessions with $\mathrm{A}$ and $\mathrm{C}$ to give the mean training consumption of $\mathrm{CS}+$ solutions. Similarly, mean CS - consumption was calculated by averaging across all sessions with $\mathrm{B}$ and $\mathrm{D}$ : mean consumption per session of the CS + and CS - was $13.5 \mathrm{~g}(S E M=0.8)$ and $9.0 \mathrm{~g}(S E M=0.4)$ respectively. In Group Paired, the mean training phase consumption of the $\mathrm{CS}+(\mathrm{AC})$ and $\mathrm{CS}-(\mathrm{BD})$ was $12.2 \mathrm{~g}$ $(S E M=1.0)$ and $8.0 \mathrm{~g}(S E M=0.8)$ respectively. These data were analyzed using ANOVA with group (Individual or Paired) and stimulus $(\mathrm{CS}+$ or $\mathrm{CS}-)$ as factors. There was a significant effect of stimulus, $F(1,30)=73.58, p<.001$, indicating greater consumption of the $\mathrm{CS}+$. The main effect of group approached standard levels of significance, $F(1,30)=3.84, p=.060$, indicating a trend toward slightly lower overall consumption in Group Paired. There was no interaction between stimulus and group, $F<1$.

The most critical data from Experiment $3 \mathrm{~A}$ are the consumption data from the test phase (see Figure 4A). Inspection of this figure suggests that consumption of the $\mathrm{CS}+\mathrm{s}$ was much larger than that of the $\mathrm{CS}-\mathrm{s}$ in both Groups Individual and Paired. Furthermore, the size of this difference was larger in the compound than the element tests for Group Paired, but there was no effect of test type on the difference between $\mathrm{CS}+$ and CS - consumption in Group Individual. The test data was subjected to ANOVA using a between subjects factor of Group (Individual or Paired), and withinsubjects factors of stimulus (CS + or $\mathrm{CS}-$ ) and test (Element or Compound). This analysis revealed a significant 3-way interaction between group, stimulus, and test, $F(1,30)=6.31, p=.018$. In
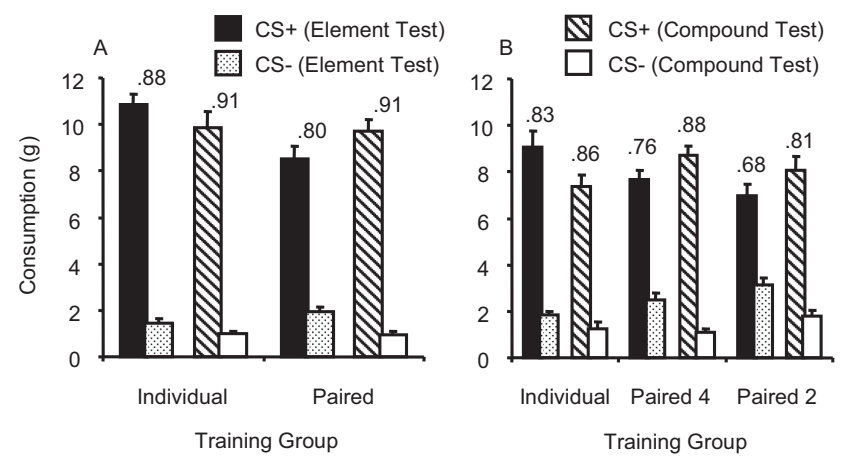

Figure 4. Panel A shows mean test consumption (with SEM) of the CS+ and $\mathrm{CS}-$ in Experiment $3 \mathrm{~A}$ for both Element and Compound tests. Panel B shows mean test consumption in Experiment 3B for both Element and Compound tests. Both $\mathrm{CS}+$ and $\mathrm{CS}-$ were presented in simultaneous compound with $2 \%$ maltodextrin during testing. Numbers adjacent to each pair of bars represent the ratio between consumption of the CS + over total consumption.

order to assess whether this interaction reflects the presence of an effect of test type on the size of the CS + versus CS - consumption difference that was present in Group Paired but not Group individual consumption of the $\mathrm{CS}$ - was subtracted from consumption of the CS+ for the element and compound tests: the size of the $\mathrm{CS}+$ versus $\mathrm{CS}-$ difference was affected by test type in Group Paired, $F(1,30)=8.14, p=.008$, but not in Group Individual, $F<1$. That is, there was no evidence for summation when individually trained CSs were presented together in compound during test.

The remainder of the ANOVA indicated that there were no significant effects of test, $F(1,30)=2.89, p=.100$, or group, $F(1$, $30)=2.28, p=.142$, suggesting that neither training or test type had any effect on overall consumption. There was an interaction between test and group, $F(1,30)=4.38, p=.045$. Further inspection of Figure 4A suggests that consumption was higher when animals were tested in conditions that were analogous to their training (i.e., the element test for Group Individual and the compound test for Group Paired) although simple-effect analyses indicate that this difference was only significant in Group Individual, $F(1,30)=7.19, p=.012$ and $F<1$, respectively. There was a significant effect of stimulus, $F(1,30)=560.62, p<.001$, and an interaction between group and stimulus, $F(1,30)=4.65, p=$ .039 , but not between stimulus and test, $F(1,30)=2.32, p=.138$.

To further examine the effects of summation within Experiment $3 \mathrm{~A}$ and to facilitate comparisons between Experiments $3 \mathrm{~A}$ and $3 \mathrm{~B}$ the preference ratio for the $\mathrm{CS}+$ was calculated as $(\mathrm{CS}+$ consumption $) /(\mathrm{CS}+$ consumption $+\mathrm{CS}-$ consumption $)$. These preference data (see Figure 4A) are consistent with the consumption data in that the size of the preference for the $\mathrm{CS}+$ appears to be unaffected by test type in Group Individual but that the preference was larger on the compound than element tests in Group Paired.

These data were analyzed using ANOVA with a betweensubjects factor of group (Individual or Paired), and a withinsubject factor of test (Element or Compound). This revealed a significant effect of test, $F(1,30)=17.55, p<.001$, and that the effect of group did not reach significance, $F(1,30)=4.09, p=$ .052. Most important, there was a significant interaction between 
test and group, $F(1,30)=6.47, p=.016$. Consistent with the analysis of the consumption data, simple-effect analyses indicate that Group Paired showed a greater preference for the CS + on the compound test than the element tests, $F(1,30)=22.66, p<.001$, but that there was no effect of test type on the preference for the $\mathrm{CS}+$ in Group Individual, $F(1,30)=1.36, p=.254$.

\section{Experiment 3B}

The training phase data were treated as in Experiment 3A. Mean consumption of the $\mathrm{CS}+$ and $\mathrm{CS}-$ per session in Group Individual was $12.8 \mathrm{~g}(S E M=1.0)$ and $8.7 \mathrm{~g}(\mathrm{SEM}=0.8)$ respectively. In Group Paired $4 \mathrm{CS}+$ and CS - consumption was $12.2 \mathrm{~g}($ SEM $=$ $0.9)$ and $8.0 \mathrm{~g}(S E M=0.4)$ and in Group Paired $2 \mathrm{CS}+$ and $\mathrm{CS}-$ consumption was $12.5 \mathrm{~g}(S E M=1.1)$ and $8.9 \mathrm{~g}($ SEM $=0.9)$. These data were analyzed using ANOVA with group (Individual or Paired) and stimulus (CS+ or $\mathrm{CS}-$ ) as factors. There was a significant effect of stimulus $[F(1,30)=48.56, p<.001]$, indicating greater consumption of $\mathrm{CS}+\mathrm{s}$ than $\mathrm{s} C \mathrm{CS}-\mathrm{s}$ across training, but no effect of group nor any interaction $\left[F_{\mathrm{S}}<1\right]$.

Figure 4B shows the consumption data for the test phase. Inspection of this figure suggests that consumption of the CS+ was greater than the $\mathrm{CS}-$ in all groups and conditions (and that the difference was smaller than in Experiment 3A). Most important, the size of the CS + versus CS - difference was unaffected by test type in Group Individual, but was larger in the compound than element tests for both Group Paired 2 and Group Paired 4. Thus, as in Experiment 3A, there was no suggestion of a summation effect when individually trained CSs were presented in compound during test. The consumption data were subjected to ANOVA using a between-subjects factor of group (Individual, Paired 2, or Paired 4), and within-subjects factors of stimulus (CS+ or CS-) and test (Element or Compound). This revealed a significant 3-way interaction between group, stimulus, and test, $F(2,45)=10.60$, $p<.001$. As in Experiment $3 \mathrm{~A}$ this interaction was examined by subtracting consumption of the CS - from consumption of the $\mathrm{CS}+$ : The size of the $\mathrm{CS}+\mathrm{v} \mathrm{CS}-$ difference was numerically, but not significantly, larger in the element test than the compound test in Group Individual, $F(1,45)=3.06, p=.087$, while in both of Groups Paired 4 and Paired 2 the size of the CS+ v CSdifference was significantly larger in the compound than in the element tests, $F(1,45)=15.10, p<.001$ and $F(1,45)=15.15$, $p<.001$, respectively. Thus there was no suggestion of a summation effect in Group Individual (indeed, there was a trend in the opposite direction).

The remainder of the ANOVA revealed no significant effect of group, $F<1$, indicating that training type had no effects on overall consumption. There was an effect of test, $F(1,45)=9.63, p=$ .003 , reflecting higher overall consumption in the element tests as well as a significant Test $\times$ Group interaction, $F(2,45)=4.70$, $p=.016$. Simple-effect analyses of this interaction revealed that consumption was higher in the element test only for Group Individual, $F(1,45)=18.14, p<.001$ but not in either of Groups Paired 2 or Paired 4, $F \mathrm{~s}<1$. There was also a significant effect of stimulus, $F(1,45)=427.93, p<.001$. There was no significant interaction between stimulus and group, $F(2,45)=2.98, p=.061$, but there was an interaction between stimulus and test, $F(1,45)=$ $18.88, p=.001$.
Figure $4 \mathrm{~B}$ also shows the preference ratio for the $\mathrm{CS}+$. This is consistent with the consumption data in that the size of the preference for the CS + appears to be unaffected by test type in Group Individual but that the preference was larger on the compound than element tests for both of the other groups. These data were analyzed using ANOVA between subjects factor of group (Individual, Paired 2, or Paired 4), and a within-subject factor of test (Element or Compound). There were significant effects of group, $F(2,45)=$ $8.18, p=.001$, Test, $F(1,45)=31.27, p<.001$, and a Test $\times$ Group interaction, $F(2,45)=3.60, p=.036$. For Group Individual there was no difference between the element and compound tests in the size of the CS+ preference, $F(1,45)=1.08, p=.304$, but that in both of Groups Paired 4 and Paired 2 the CS+ preference was higher in the compound test, $F(1,45)=18.92, p<$ .001 and $F(1,45)=18.47, p<.001$, respectively.

\section{Discussion - Experiment 3}

In both of Experiments $3 \mathrm{~A}$ and $3 \mathrm{~B}$, the analysis of raw consumption and $\mathrm{CS}+$ preference data indicates that after training with two separate $\mathrm{CS}+\mathrm{s}(\mathrm{A}$ and $\mathrm{C})$ and two $\mathrm{CS}-\mathrm{s}(\mathrm{B}$ and $\mathrm{D})$ the size of the preference for the CS+ over the CS- was no greater when the CSs were combined as compared to when they were tested alone. That is, there is no evidence for a summation effect. However, there was an effect of test type in animals that were given initial training with the $\mathrm{CSs}$ in pairs (i.e., $\mathrm{AC}+$ and $\mathrm{BD}-$ ). In these groups the preference for the $\mathrm{CS}+$ over the $\mathrm{CS}-$ was attenuated when the CSs were tested alone as compared to when they were tested in compound, which is indicative of an overshadowing effect. Such overshadowing effects imply that the failure to observe summation was not due to a failure to process the CSs differently when presented as elements and compounds. Moreover, although the overall preference for the $\mathrm{CS}+$ in Experiment $3 \mathrm{~A}$ was high, it was lower in Experiment $3 \mathrm{~B}$ and so it is unlikely that ceiling effects are responsible for the failure to see summation here. Indeed, a further analysis of the $\mathrm{CS}+$ preference ratio data from Experiments $3 \mathrm{~A}$ and $3 \mathrm{~B}$ (using only the Individual trained groups) revealed a significant effect of experiment, $F(1,30)=$ $8.07, p=.008$, but no effect of test, $F(1,30)=1.72, p=.199$, or interaction between test and experiment, $F<1$. That is, a difference in overall preference sizes had no effect on the critical observation of a lack of a difference between element and compound tests in terms of the size of the CS+ preference. Furthermore, even when statistical power is increased by combining the data from both experiments there is still no suggestion of summation.

The question of whether stimuli are best considered to be processed as elements or as configurations has been central to debates over modern theories of associative learning. The examination of summation has been a central feature of this debate because, simply conceived, elemental theories tend to predict that summation should occur while configural theories predict the absence of summation (for recent reviews see Pearce, 2002; Soto, Vogel, Castillo, \& Wagner, 2009; Wagner, 2003). Thus the present data would appear to fit most naturally with a configural understanding of conditioning in general and of flavor preference in particular (e.g., Capaldi \& Hunter, 1994; Harris \& Thein, 2005; Pearce, 2002; and the model described above). We will return to this issue in the General Discussion. 


\section{General Discussion}

The initial aim of this series of experiments was to examine cue competition, in the form of overshadowing and blocking, in flavor preference learning. In contrast to some previous reports we observed consistent effects of both overshadowing and blocking in both between- (Experiments 1A-1C) and with-subjects designs (Experiments 2A-2C). The discrepancy between the current results and those reported by Capaldi and Privitera (2008) and by Holder (1991) was discussed in terms of a configural analysis which suggests that the critical factor in whether cue competition is observed or not is the degree of generalization between a compound and its elements. That is, when generalization between a compound and its elements is weak then both overshadowing and blocking will be observed but when generalization is substantial then overshadowing will be reduced (and prior to asymptote potentiation should occur) but blocking should still be present. In addition to providing an account of the results of Experiments 1 and 2 this configural model predicted that summation should not occur when the parameters favor the observation of overshadowing. The results of Experiments $3 \mathrm{~A}$ and $3 \mathrm{~B}$ were consistent with this prediction because summation was not observed using stimulus parameters that were similar to those used to produce overshadowing in Experiments $2 \mathrm{~A}$ and $2 \mathrm{~B}$.

Thus the configural model we have described here as an account of the apparently inconsistent results of cue-competition studies in flavor preference learning has passed at least its initial test in accurately predicting the absence of summation with the parameters in use here. More rigorous tests of this model will be produced by further empirical studies examining its other predictions: That summation will be observed when the stimulus parameters favor potentiation or the absence of overshadowing; that overshadowing should be enhanced, and potentiation diminished, by extended training; and that blocking should be greater when generalization between compounds and their elements is high than when it is low (that is, the size of blocking and overshadowing effects should be inversely related). We are aware of no existing data that directly addresses any of these issues. ${ }^{2}$

The model presented above took as its starting point the idea that a consideration of configural processes and generalization might provide an account of the different results observed in studies of cue competition in flavor preference learning. In this light it is interesting that there have already been a number of suggestions that flavor preference learning might rely on specifically configural, rather than elemental, learning processes (e.g., Capaldi \& Hunter, 1994; Harris \& Thein, 2005; Pearce, 2002). However, the evidence cited in support of these ideas was less than conclusive because both elemental and configural approaches are consistent with the vast majority of previously reported flavor preference conditioning studies (Dwyer, 2005, 2008; Dwyer \& Quirk, 2008). The same cannot be said of the results of Experiments $3 \mathrm{~A}$ and $3 \mathrm{~B}$. Many elemental theories follow the assumption embodied in the Rescorla and Wagner (1972) model that the associative strength of a compound stimulus will simply be the sum of the associative strengths of its individual components. Therefore, such theories predict that the compound of two cues trained separately will have a greater associative strength than either stimulus alone and thus responding should be greater to the compound than to either of its constituent elements. That is, responding is expected to summate. In contrast, the configural approach described by Pearce (e.g., 1994, 2002) does not anticipate summation, and so the present results are consistent with the view that flavor preference learning does, in a very general sense, reflect configural rather than elemental mechanisms.

While the current failure to observe summation is inconsistent with early elemental theories of conditioning (e.g., Rescorla \& Wagner, 1972) it should be noted that models of conditioning that assume elemental processing have been developed that can account for the fact that summation is only inconsistently reported. For example, Wagner's (2003) replaced elements model suggests that when a stimulus is presented as part of a compound a proportion of the elements normally activated by that stimulus when presented alone will be inhibited and will be replaced by a separate set of elements that are only activated when the stimulus is presented as part of a particular compound. When the proportion of these context-sensitive elements is large summation will be reduced because each element will activate a rather different set of elements when presented alone to when it is in compound. Thus the fact that we have observed an absence of summation here is only inconsistent with elemental models that have not been developed to deal with the challenges proposed by configural accounts. That said, while the replaced elements model (Wagner, 2003) can explain why summation is observed under some circumstances (low levels of context sensitive replacement) and not others (high levels of replacement) the model predicts that overshadowing will occur under both sets of circumstances. Moreover, the replaced elements model is not capable of accounting for potentiation. Thus it cannot explain the previous studies of flavor preference conditioning where either potentiation (Capaldi \& Privitera, 2008) or an absence of overshadowing (Holder, 1991) were observed. It is important that neither Wagner's (2003) replaced elements model nor Pearce's $(1994,2002)$ configural model includes any consideration of the role of generalization in accounting for the degree of summation. Thus neither share the prediction made here that summation will be observed only when the stimulus parameters favor the observation of potentiation or the absence of overshadowing.

Flavor preferences have, until this point, been discussed in an undifferentiated fashion. However, it is important to note that a distinction has been drawn between preferences where nutrients are the reinforcer and preferences where reinforcement is provided by a palatable taste alone (e.g., Capaldi, 1992; Myers \& Sclafani, 2006). While both palatability- and nutrient-based preferences result in greater preferential consumption of a CS+ over a CSflavour there is good evidence that the two processes can be dissociated experimentally (e.g., Harris, Gorissen, Bailey, \& West-

\footnotetext{
${ }^{2}$ A comparison across experiments reported by Balleine, Espinet, and Gonzalez (2005) may appear relevant to the last prediction. In Experiment 2 generalization between stimuli was reduced by a perceptual learning treatment but in Experiment 1 there was no such pretraining perceptual learning and the degree of blocking was numerically larger in Experiment 2 than in Experiment 1. However, while the perceptual learning treatment used by Balleine et al. (2005) should reduce generalization between the different elements of a compound there is no evidence that it also reduces generalization between the compound and one or other of its constituent elements. Thus this study does not address the predictions of the current model.
} 
brook, 2000; Warwick \& Weingarten, 1994). Furthermore, there is some evidence that they may rely on different psychological mechanisms as palatability- and nutrient-based learning appear to affect appetitive and consummatory responding differently (Myers \& Hall, 1998) and manipulations of the temporal relationship between CS and US appear to affect palatability-based preferences more than nutrient-based preferences (e.g., Holman, 1975; Sclafani \& Ackroff, 1994). Maltodextrin selectively supports nutrientbased preferences as its taste alone is generally ineffective in conditioning a preference when nutrient effects are minimized (Bonacchi, Ackroff, \& Sclafani, 2008; Elizalde \& Sclafani, 1988). Therefore, it is possible that the results reported in all the current experiments might be restricted to nutrient-based conditioning and that a different result might be obtained with palatability-based preferences. While this is a matter for empirical verification, the previous evidence for flavor preference learning as a configural process is arguably stronger for palatability-based than for nutrient-based preferences (Dwyer \& Quirk, 2008), and so we would expect that palatability-based preferences would also produce results consistent with our configural model.

Whatever the merits of the various analyses of the effects of compound conditioning on flavor preference learning that have been discussed here, they demonstrate how existing theories of conditioning can be applied to the study of flavor preference learning in general and to cue-competition and summation in particular. We have advocated here a configural perspective and have argued that it can provide an account for why under some circumstances cue-competition may be evident, but under other circumstances may not. It remains to be determined with further experiments whether the properties of flavor preference learning continue to justify this perspective and also whether it can be reconciled with observations regarding Pavlovian conditioning from outside the flavor domain.

\section{References}

Balleine, B. W., Espinet, A., \& Gonzalez, F. (2005). Perceptual learning enhances retrospective revaluation of conditioned flavor preferences in rats. Journal of Experimental Psychology-Animal Behavior Processes, 31, 341-350.

Batsell, W. R., Jr., \& Paschall, G. Y. (2009). Mechanisms of compound conditioning in flavor-aversion conditioning. In S. Reilly \& T. R. Schachtman (Eds.), Conditioned taste aversion: Behavioral and neural processes (pp. 179-195). Oxford: Oxford University Press.

Blaser, R. E., Couvillon, P. A., \& Bitterman, M. E. (2008). Within-subjects experiments on blocking and facilitation in honeybees (Apis mellifera). Journal of Comparative Psychology, 122, 373-378.

Bonacchi, K. B., Ackroff, K., \& Sclafani, A. (2008). Sucrose taste but not Polycose taste conditions flavor preferences in rats. Physiology \& Behavior, 95, 235-244.

Bouton, M. E., Dunlap, C. M., \& Swartzentruber, D. (1987). Potentiation of taste by another taste during compound aversion learning. Animal Learning \& Behavior, 15, 433-438.

Campbell, D. H., Capaldi, E. D., Sheffer, J. D., \& Bradford, J. P. (1988). An examination of the relationship between expectancy learning and preference conditioning. Learning and Motivation, 19, 162-182.

Capaldi, E. D. (1992). Conditioned food preferences. The Psychology of Learning and Motivation, 28, 1-33.

Capaldi, E. D., \& Hunter, M. J. (1994). Taste and odor in conditioned flavor preference learning. Animal Learning \& Behavior, 22, 355-365.

Capaldi, E. D., Myers, D. E., Campbell, D. H., \& Sheffer, J. D. (1983).
Conditioned flavor preferences based on hunger level during original flavor exposure. Animal Learning \& Behavior, 19, 362-368.

Capaldi, E. D., \& Privitera, G. J. (2008). Potentiation of taste and extract stimuli in conditioned flavor preference learning. Learning \& Behavior, $36,62-66$.

Chamizo, V. D., Aznar-Casanova, J. A., \& Artigas, A. A. (2003). Human overshadowing in a virtual pool: Simple guidance is a good competitor against locale learning. Learning and Motivation, 34, 262-281.

Delamater, A. R. (2007). Extinction of conditioned flavor preferences. Journal of Experimental Psychology-Animal Behavior Processes, 33, $160-171$.

Dickinson, A., Shanks, D., \& Evenden, J. (1984). Judgement of actoutcome contingency: The role of selective attribution. Quarterly Journal of Experimental Psychology. A, Human Experimental Psychology, 36, 29-50.

Dopson, J. C., Pearce, J. M., \& Haselgrove, M. (2009). Failure of Retrospective Revaluation to Influence Blocking. Journal of Experimental Psychology-Animal Behavior Processes, 35, 473-484.

Drucker, D. B., Ackroff, K., \& Sclafani, A. (1994). Nutrient-conditioned flavor preference and acceptance in rats: Effects of deprivation state and nonreinforcement. Physiology \& Behavior, 56, 701-707.

Durlach, P. J., \& Rescorla, R. A. (1980). Potentiation rather than overshadowing in flavor-aversion learning: An analysis in terms of withincompound associations. Journal of Experimental Psychology: Animal Behavior Processes, 6, 175-187.

Dwyer, D. M. (2000). Formation of a novel preference and aversion by simultaneous activation of the representations of absent cues. Behavioural Processes, 48, 159-164.

Dwyer, D. M. (2005). Reinforcer devaluation in palatability-based learned flavor preferences. Journal of Experimental Psychology-Animal Behavior Processes, 31, 487-492.

Dwyer, D. M. (2008). Microstructural analysis of conditioned and unconditioned responses to maltodextrin. Learning \& Behavior, 36, 149-158.

Dwyer, D. M., Mackintosh, N. J., \& Boakes, R. A. (1998). Simultaneous activation of the representation of absent cues results in the formation of an excitatory association between them. Journal of Experimental Psychology: Animal Behavior Processes, 24, 163-171.

Dwyer, D. M., Pincham, H. L., Thein, T., \& Harris, J. A. (2009). A learned flavor preference persists despite the extinction of conditioned hedonic reactions to the cue flavors. Learning \& Behavior, 37, 305-310.

Dwyer, D. M., \& Quirk, R. H. (2008). Context conditional flavor preferences in the rat based on fructose and maltodextrin reinforcers. Journal of Experimental Psychology-Animal Behavior Processes, 34, 294-302.

Elizalde, G., \& Sclafani, A. (1988). Starch-based conditioned flavor preferences in rats - influence of taste, calories and Cs-Us delay. Appetite, 11, 179-200.

Elizalde, G., \& Sclafani, A. (1990). Flavor preferences conditioned by intragastric polycose infusions - a detailed analysis using an electronic esophagus preparation. Physiology \& Behavior, 47, 63-77.

Grand, C., Close, J., Hale, J., \& Honey, R. C. (2007). The role of similarity in human associative learning. Journal of Experimental PsychologyAnimal Behavior Processes, 33, 64-71.

Harris, J. A., Gorissen, M. C., Bailey, G. K., \& Westbrook, R. F. (2000). Motivational state regulates the content of learned flavor preferences. Journal of Experimental Psychology-Animal Behavior Processes, 26, $15-30$.

Harris, J. A., Shand, F. L., Carroll, L. Q., \& Westbrook, R. F. (2004). Persistence of preference for a flavor presented in simultaneous compound with sucrose. Journal of Experimental Psychology-Animal Behavior Processes, 30, 177-189.

Harris, J. A., \& Thein, T. (2005). Interactions between conditioned and unconditioned flavor preferences. Journal of Experimental PsychologyAnimal Behavior Processes, 31, 407-417.

Holder, M. D. (1991). Conditioned preferences for the taste and odor 
components of flavors: Blocking but not overshadowing. Appetite, 17, $29-45$.

Holland, P. C. (1999). Overshadowing and blocking as acquisition deficits: No recovery after extinction of overshadowing or blocking cues. QJEP, 52B, 307-333.

Holman, E. W. (1975). Immediate and delayed reinforcers for flavor preferences in rats. Learning and Motivation, 6, 91-100.

Hull, C. L. (1949). Stimulus intensity dynamism (V) and stimulus generalization. Psychological Review, 56, 67-76.

Kamin, L. J. (1969). Selective association and conditioning. In N. J. Mackintosh \& W. K. Honig (Eds.), Fundamental issues in associative learning (pp. 42-64). Halifax: Dalhousie University Press.

Kinder, A., \& Lachnit, H. (2003). Similarity and discrimination in human Pavlovian conditioning. Psychophysiology, 40, 226-234.

Kucharski, D., \& Spear, N. E. (1985). Potentiation and Overshadowing in Preweanling and Adult-Rats. Journal of Experimental PsychologyAnimal Behavior Processes, 11, 15-34.

Le Pelley, M. E., Oakeshott, S. M., \& McLaren, I. P. L. (2005). Blocking and unblocking in human causal learning. Journal of Experimental Psychology-Animal Behavior Processes, 31, 56-70.

Mackintosh, N. J. (1971). An analysis of overshadowing and blocking. Quarterly Journal of Experimental Psychology, 23, 118-125.

Mackintosh, N. J. (1975). A theory of attention: Variations in the associability of stimuli with reinforcement. Psychological Review, 82, 276298.

Myers, K. P., \& Hall, W. G. (1998). Evidence that oral and nutrient reinforcers differentially condition appetitive and consummatory responses to flavors. Physiology \& Behavior, 64, 493-500.

Myers, K. P., \& Sclafani, A. (2006). Development of learned flavor preferences. Developmental Psychobiology, 48, 380-388.

Pavlov, I. P. (1927). Conditioned reflexes. London: Oxford University Press.

Pearce, J. M. (1987). A model for stimulus generalization in Pavlovian conditioning. Psychological Review, 94, 61-73.

Pearce, J. M. (1994). Similarity and discrimination - a selective review and a connectionist model. Psychological Review, 101, 587-607.

Pearce, J. M. (2002). Evaluation and development of a connectionist theory of configural learning. Animal Learning \& Behavior, 30, 73-95.

Pearce, J. M., Esber, G. P., George, D. N., \& Haselgrove, M. (2008). The nature of discrimination learning in pigeons. Learning \& Behavior, 36, $188-199$.

Pearce, J. M., Graham, M., Good, M. A., Jones, P. M., \& McGregor, A. (2006). Potentiation, overshadowing, and blocking of spatial learning based on-the shape of the environment. Journal of Experimental Psychology-Animal Behavior Processes, 32, 201-214.

Pearce, J. M., \& Hall, G. (1980). A model for Pavlovian learning: Variations in the effectiveness of conditioned but not of uncondidtioned stimuli. Psychological Review, 87, 352-552.

Rescorla, R. A. (1981). Within-signal learning in autoshaping. Animal Learning \& Behavior, 9, 245-252.

Rescorla, R. A., \& Durlach, P. J. (1981). Within-Event learning in Pav- lovian Conditioning. In N. E. Spear \& R. Miller (Eds.), Information processing in animals: Memory mechanisms (pp. 81-111). Hillsdale, NJ: Erlbaum, Associates, Inc.

Rescorla, R. A., \& Furrow, D. R. (1977). Stimulus similarity as a determinant of Pavlovian conditioning. Journal of Experimental Psychology: Animal Behavior Processes, 3, 203-215.

Rescorla, R. A., \& Gillan, D. J. (1980). An analysis of the facilitative effect of similarity on 2nd-order conditioning. Journal of Experimental Psychology-Animal Behavior Processes, 6, 339-351.

Rescorla, R. A., \& Wagner, A. R. (1972). A theory of Pavlovian conditioning: Variations in the effectiveness of reinforcement and nonreinforcement. In A. H. Black \& W. F. Prokasy (Eds.), Classical conditioning II: Current theory and research. (pp. 64-99). New York: Appelton-Century-Crofts.

Revusky, S. (1971). The role of interference in association over a delay. In W. K. H. a. P. H. R. James (Ed.), Animal memory (pp. 155-213). New York: Academic Press.

Rodrigo, T., Chamizo, V. D., McLaren, I. P. L., \& Mackintosh, N. J. (1997). Blocking in the spatial domain. Journal of Experimental Psychology-Animal Behavior Processes, 23, 110-118.

Rusiniak, K. W., Hankins, W. G., Garcia, J., \& Brett, L. P. (1979). Flavor-illness aversions: Potentiation of odor by taste in rats. Behavioral and Neural Biology, 25, 1-17.

Schnelker, J., \& Batsell, W. R., Jr. (2006). Within-compound associations are not sufficient to produce taste-mediated odor potentiation. Behavioural Processes, 73, 142-148.

Sclafani, A., \& Ackroff, K. (1994). Glucose-conditioned and fructoseconditioned flavor preferences in rats - taste versus postingestive conditioning. Physiology \& Behavior, 56, 399-405.

Slotnick, B. M., Westbrook, F., \& Darling, F. M. C. (1997). What the rat's nose tells the rat's mouth: Long delay conditioning with aqueous odors and potentiation taste by odors. Animal Learning \& Behavior, 25, 357-369.

Soto, F. A., Vogel, E. H., Castillo, R. D., \& Wagner, A. D. (2009). Generality of the summation effect in human causal learning. Quarterly Journal of Experimental Psychology, 62, 877-889.

Tennant, W. A., \& Bitterman, M. E. (1975). Blocking and overshadowing in 2 species of fish. Journal of Experimental Psychology, 104, 22-29.

Trost, C. A., \& Batsell, W. R. (2004). Taste plus odor interactions in compound aversion conditioning. Learning \& Behavior, 32, 440-453.

Wagner, A. R. (2003). Context-sensitive elemental theory. Quarterly Journal of Experimental Psychology Section B-Comparative and Physiological Psychology, 56, 7-29.

Warwick, Z. S., \& Weingarten, H. P. (1994). Dissociation of Palatability and Calorie Effects in Learned Flavor Preferences. Physiology \& Behavior, 55, 501-504.

Willner, J. A. (1978). Blocking of a taste-aversion by prior pairings of exteroceptive stimuli with illness. Learning and Motivation, 9, 125-140.

Received August 20, 2009

Revision received May 25, 2010 Accepted June 1, 2010 